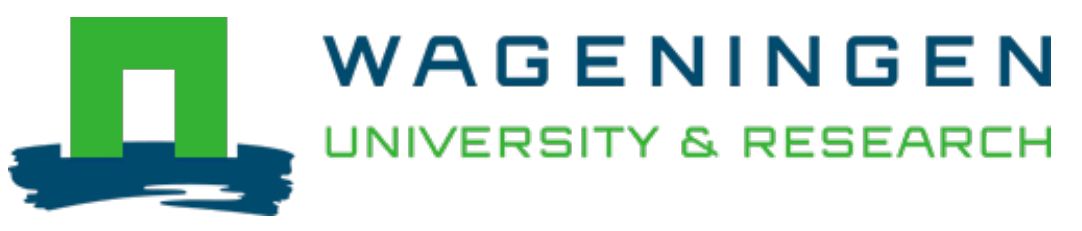

\title{
An explorative study on the relationships between the quality traits of peanut varieties and their peanut butters
}

Food Science and Technology = Lebensmittel-Wissenschaft und Technologie

Yu, Hongwei; Liu, Hongzhi; Erasmus, Sara W.; Zhao, Simeng; Wang, Qiang et al

https://doi.org/10.1016/j.lwt.2021.112068

This publication is made publicly available in the institutional repository of Wageningen University and Research, under the terms of article $25 \mathrm{fa}$ of the Dutch Copyright Act, also known as the Amendment Taverne. This has been done with explicit consent by the author.

Article 25 fa states that the author of a short scientific work funded either wholly or partially by Dutch public funds is entitled to make that work publicly available for no consideration following a reasonable period of time after the work was first published, provided that clear reference is made to the source of the first publication of the work.

This publication is distributed under The Association of Universities in the Netherlands (VSNU) 'Article $25 \mathrm{fa}$ implementation' project. In this project research outputs of researchers employed by Dutch Universities that comply with the legal requirements of Article $25 \mathrm{fa}$ of the Dutch Copyright Act are distributed online and free of cost or other barriers in institutional repositories. Research outputs are distributed six months after their first online publication in the original published version and with proper attribution to the source of the original publication.

You are permitted to download and use the publication for personal purposes. All rights remain with the author(s) and / or copyright owner(s) of this work. Any use of the publication or parts of it other than authorised under article $25 \mathrm{fa}$ of the Dutch Copyright act is prohibited. Wageningen University \& Research and the author(s) of this publication shall not be held responsible or liable for any damages resulting from your (re)use of this publication.

For questions regarding the public availability of this publication please contact openscience.library@wur.nl 


\title{
An explorative study on the relationships between the quality traits of peanut varieties and their peanut butters
}

\author{
Hongwei Yu $^{\text {a,b }}$, Hongzhi Liu ${ }^{\text {a }}$, Sara W. Erasmus ${ }^{\text {b }}$, Simeng Zhao ${ }^{\text {a }}$, Qiang Wang ${ }^{\text {a, }}$, Saskia M. van \\ Ruth ${ }^{\mathrm{b}, \mathrm{c}}$ \\ ${ }^{a}$ Institute of Food Science and Technology, Chinese Academy of Agricultural Sciences/Key Laboratory of Agro-Products Processing, Ministry of Agriculture and Rural \\ Affairs, P.O. Box 5109, Beijing, 100193, China \\ ${ }^{\mathrm{b}}$ Food Quality and Design, Wageningen University and Research, P.O. Box 17, 6700, AA, Wageningen, the Netherlands \\ ${ }^{\mathrm{c}}$ Institute for Global Food Security, School of Biological Sciences, Queen's University, 19 Chlorine Gardens, Belfast BT9 5DL, Northern Ireland, United Kingdom
}

\section{A R T I C L E I N F O}

\section{Keywords:}

Cluster analysis

Correlation analysis

Principal component analysis

Texture and rheology

Volatile compounds

\begin{abstract}
A B S T R A C T
Peanut varieties have their own distinct characteristics, which also affect the properties of the processedproducts. Knowledge on these effects can assist peanut processors to select certain varieties for specific products. Therefore, the multivariate relationships between the quality traits of peanut kernels and their peanut butters were explored in this study. Peanut butters were manufactured from forty peanut varieties with detailed component analysis. The volatile compounds, colour, texture, rheology, and particle size distributions of peanut butters and their relationships with peanut varieties were comprehensively analysed. The results showed that peanut butters prepared from varieties with lower fat, higher protein, and higher sucrose contents have higher firmness, yield stress, and $G^{\prime}$ values. It was also suggested that amino acids likely play a major role in the formation of the distinct peanut butter aroma and colour. This research study provided a detailed analysis approach that can be used by processing enterprises to select the most suitable varieties to produce peanut butters that address different commercial needs.
\end{abstract}

\section{Introduction}

Peanut butters are dense suspensions of solid flecks diffused in a continuous oil phase (Norazatul Hanim, Chin, \& Yusof, 2016). Globally, it is one of the most consumed and important plant-based spreads which has a special flavour and mouthfeel (Gong et al., 2018), while it also offers health benefits such as inhibiting the risk of gastric cancer (Hashemian et al., 2017). Nowadays, the industrial scale production of peanut butter is extensively developed and generally processed by subjecting raw peanuts to roasting and grinding. Peanuts form the material basis of peanut butter and hence the quality of the intact peanuts can subsequently affect the quality characteristics of its resulting peanut butter.

Peanuts are identified as one of the leading produced, processed, and traded nuts in the world (Wang, 2018). There are more than 8000 peanut varieties and strains worldwide which differ considerably in their compositions (Q. Wang, Adhikari, \& Hung, 2017). The quality requirement of peanuts to produce different types of products like peanut tofu, peanut oil, and peanut butter vary substantially. It is well-known that the amino acids contents such as cystine and lysine play a vital role in peanut protein (L. Wang et al., 2017c) and peanut tofu (Chen et al., 2020). It has also been discovered that peanuts with higher oleic acid contents result in better peanut oils after processing (Wang, 2018). The acceptability of peanut butter is linked to various quality traits that includes its volatile compounds, colour, texture, rheology, and particle size distributions (Shakerardekani, Karim, Ghazali, \& Chin, 2013; Starowicz \& Zieliński, 2019). Most studies have only focused on one or two quality traits of peanut butters from a few varieties. For example, Mohd Rozalli, Chin, and Yusof (2015) focused on the diameter of particles and the dynamic rheological qualities of peanut butters, showing that peanut butters have elastic properties. Norazatul Hanim et al. (2016) discovered that two peanut varieties resulted in different particle size distributions of peanut butters. The volatiles of two different peanut butters have also been studied, indicating that pyrazines are the main aroma components of peanut butters (Lou et al., 2009). Some scientists (Dhamsaniya, Patel, \& Dabhi, 2012; Gong et al., 2018) have already conducted research on the impacts of different fat, protein, and fatty acids contents of peanuts on the sensory properties of

\footnotetext{
* Corresponding author.

E-mail address: wangqiang06@caas.cn (Q. Wang).
} 
peanut butters and its stability during the storage. Although some relationships between peanuts and the resulting peanut butters have been revealed, the picture is not yet complete.

More in-depth knowledge about the relationships and interactions that exist between quality traits of peanut kernels and peanut butters is valuable for the development of new, nutritious, and tasteful products. This quality appraisal of peanuts is not only necessary to select productspecific varieties for satisfying the commercial demands of markets, but also to better allocate how the raw material should be used to increase the sustainability of the industry. Hence, the first aim of the research was to comprehensively analyse the properties of forty peanut varieties, i.e. physical traits and composition, as well as the properties and quality traits of the resulting peanut butters. The latter included measurements of the volatile compounds, colour, texture, rheology, and particle size distributions. Subsequently, univariate comparisons and multivariate comparisons were conducted on peanut kernels and peanut butters to explore the relationships between traits for each group. Lastly, the relationships between peanut varieties and peanut butters were also elucidated.

\section{Materials and methods}

\subsection{Peanuts and peanut butters}

Forty peanut varieties were collected from different provinces in China (the details are listed in Appendix supplement 1 ). After collection, the unshelled peanuts (approximately $5 \mathrm{~kg}$ per sample) were kept in refrigerated storage units $\left(4^{\circ} \mathrm{C}\right.$, Yuandong Co., Ltd., Tianjing, China) until further processing. Peanut butter was manufactured as follows. The peanuts per variety were shelled and about $500 \mathrm{~g}$ mature plump peanut kernels (displaying no mildew or damage) were selected. The peanut kernels were then spread in a single layer on a baking sheet and roasted for $30 \mathrm{~min}$ at $160{ }^{\circ} \mathrm{C}$ in a commercial oven with a supper and lower heating function (ROBAM Co., Ltd, Hangzhou, China). After roasting, the peanut kernels were removed from the oven and left to cool at room temperature $\left(21^{\circ} \mathrm{C}\right)$ before they were peeled for grinding. Peanut butter was produced by grinding the roasted peanut kernels twice in a colloid mill (Langfang Tongyong Machinery Co., Ltd., Hebei, China). The first grinding, that lasted for $10 \mathrm{~min}$, was to make sure that all peanut kernels were ground. The second grinding, that lasted for $30 \mathrm{~s}$, was performed to ensure a final smooth product. Ultimately, $400 \mathrm{~g}$ peanut butter was produced for each peanut variety. All peanut butters were stored at room temperature $\left(21^{\circ} \mathrm{C}\right)$ until analysis. The whole procedure and analyses performed in this study are presented in Fig. 1.

\subsection{Physical analysis of the peanuts}

The dimensions (width and length) of the peanuts were determined using a Vernier Caliper (Shanghai Tool Factory Co., Ltd., Shanghai, China) (Yu, Liu, Erasmus, et al., 2020). The width (mm) and the length (mm) of each peanut kernel are respectively the crosswise and the longitudinal distance of the mature seed (Jiang, Duan, \& Ren, 2006). Ten mature plump peanut kernels of each variety, without mildew or damage, were selected for width and length measurements. The total weight of one hundred mature plump kernels per variety were considered as weight $(\mathrm{g})$. All varieties were analysed in duplicate and the average values were calculated for all parameters.

\subsection{Compositional analysis of the peanuts}

The fat contents of the peanuts were determined by the Soxhlet extraction procedure (GB5009.6, 2016). The protein contents were established using the Kjeldahl procedure (GB5009.5, 2016) with a conversion coefficient of 5.46. Amino acids in the peanuts were evaluated following the standard method (GB5009.124, 2016), while sucrose contents were examined according to the standard method (GB5009.8, 2016) and fatty acid compositions were determined by the corresponding standard method (GB5009.168, 2016). Each analysis was performed in duplicate for each peanut variety with the average values calculated for all parameters.

\subsection{Analysis of the volatile compounds of the peanut butters}

Headspace solid-phase micro-extraction (HS-SPME) was utilized to

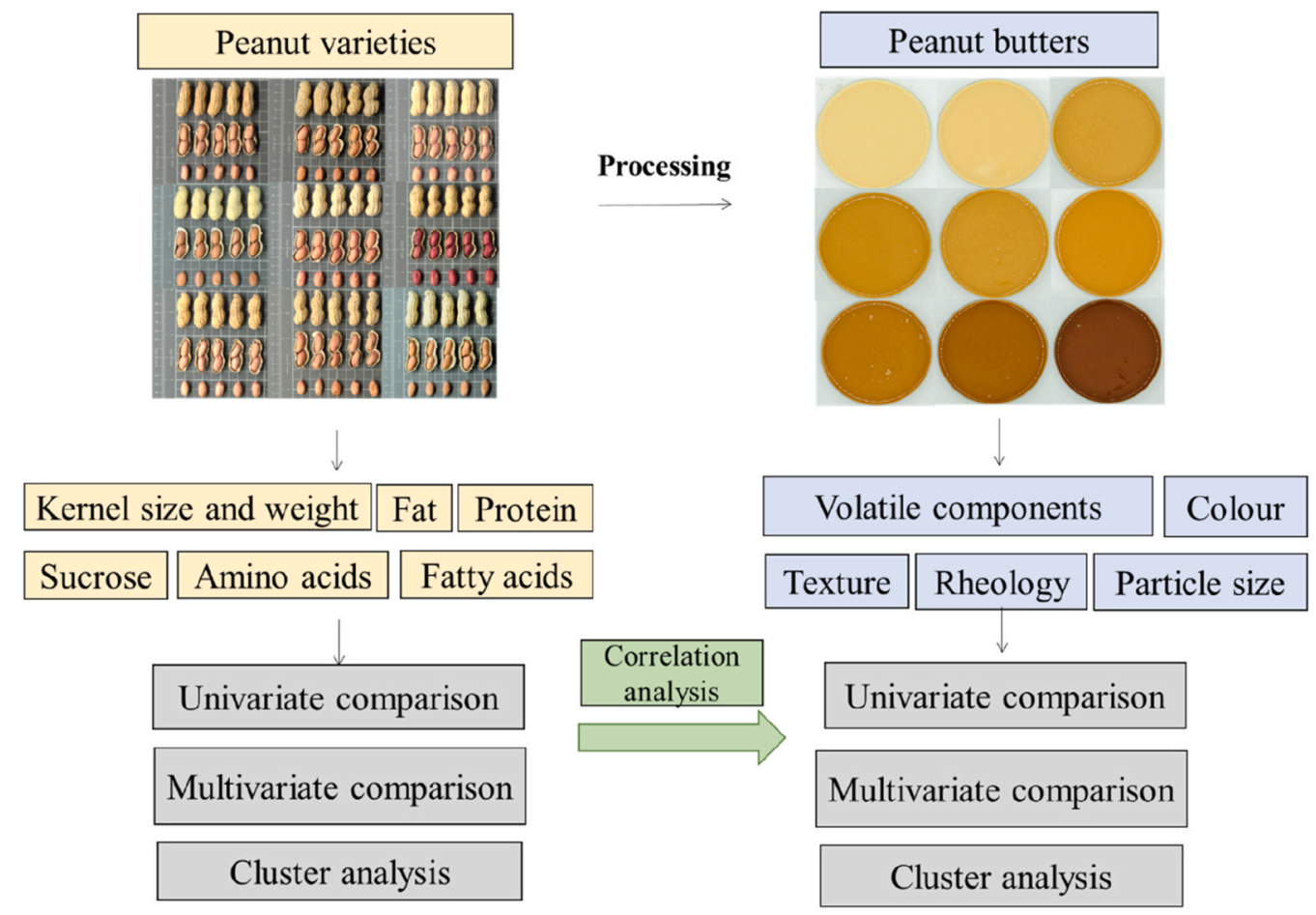

Fig. 1. The technology roadmap for the sourcing and processing of the peanuts and subsequent analyses conducted. 
determine the volatile compounds of the peanut butters. A SPME fibre (50/30 $\mu \mathrm{m}$ divinylbenzene/Carboxen/polydimethylsiloxane, Stableflex, Supelco Co., Bellefonte, USA) was pre-treated at $270{ }^{\circ} \mathrm{C}$ for $30 \mathrm{~min}$ prior to the first measurement. Each sample $(5 \mathrm{~g})$ was loaded into a $20 \mathrm{~mL}$ glass vial sealed with an aluminium cover and a Teflon septum. For quantification, $50 \mu \mathrm{L}$ 1,2,3-trichloropropane $(0.5 \mathrm{mg} / \mathrm{mL}$ in methanol, Sinopharm Chemical Reagent Co., Ltd., Beijing, China) was used as the internal standard. Each sample was pre-equilibrated for $10 \mathrm{~min}$ at $55^{\circ} \mathrm{C}$ in a shaking incubator. The SPME holder with the fibre was then embedded into the sample vial and exposed to the headspace for $40 \mathrm{~min}$ to absorb the volatile compounds. These compounds were then desorbed in the hot injection part of gas chromatography-mass spectrometry (GCMS) for $150 \mathrm{~s}$ at $260{ }^{\circ} \mathrm{C}$. The GC system (Angilent 7890B, Agilent Technologies, Santa Clara, CA) and a mass selective analyser (Angilent 5977B) equipped with a VF-MAX column ( $30 \mathrm{~m} \times 0.25 \mathrm{~mm}$ ID, $0.25 \mu \mathrm{m}$ film thickness; Angilent CP9205, Agilent Technologies, Santa Clara, CA) were used for the GC-MS analysis. The analysis was conducted in splitless mode, using helium as the carrier gas at a flow rate of $1 \mathrm{~mL} / \mathrm{min}$. The setting temperature of the analyser was $250{ }^{\circ} \mathrm{C}$, and the oven temperature program was set to start at $40{ }^{\circ} \mathrm{C}$ for $5 \mathrm{~min}$ and programmed to increase with $5{ }^{\circ} \mathrm{C} / \mathrm{min}$ to $250{ }^{\circ} \mathrm{C}$ for holding $5 \mathrm{~min}$. The electron impact ionization mode $(70 \mathrm{eV})$ was used to record the mass spectrum and scan the mass range from 35 to $500 \mathrm{~m} / \mathrm{z}$. The ion source temperature was held at $230{ }^{\circ} \mathrm{C}$. The volatile compounds were tentatively identified by comparing the sample results with the mass spectral database from the National Institute of Standards and Technology (NIST) library. In addition, an n-alkane mixed standard (C7-C40) $(0.5 \mathrm{mg} / \mathrm{mL}$ in N-hexane, o2si Smart Solutions, North Charleston, American) was run in the same conditions to obtain the retention indices (RI). The RI were calculated as stated in the formula (Eq. (1)).

$\mathrm{RI}_{\mathrm{x}}=100 \mathrm{n}+100 \times\left(\mathrm{tR}_{\mathrm{x}}-\mathrm{tR}_{\mathrm{n}}\right) /\left(\mathrm{tR}_{\mathrm{n}+1}-\mathrm{tR}_{\mathrm{n}}\right)$

where the retention time (tR) of $\mathrm{tR}_{\mathrm{n}}<\mathrm{tR}_{\mathrm{x}}<\mathrm{tR}_{\mathrm{n}+1} ; \mathrm{n}=$ number of atom carbon; $\mathrm{x}=$ one of volatile aroma compounds. Each sample was analysed in duplicate and the average values were calculated for all parameters.

\subsection{Assessment of the colour of the peanut butters}

The colour properties of the peanut butters were obtained by a CS600 portable colour spectrophotometer (CHNSpec Technology Co., Ltd, Hangzhou, China). About $2 \mathrm{~g}$ peanut butters were placed into a round quartz cell (30 mm diameter $\times 40 \mathrm{~mm}$ height) for assessment. Three different properties representing different colours were detected: $L^{*}$, darkness - lightness (0-100); $a^{*}$, greenness - redness (-128 - 127); b*, blueness - yellowness $(-128$ - 127). The procedure was repeated in triplicate for each peanut butter and the average values were calculated for all parameters.

\subsection{Assessment of the texture of the peanut butters}

The texture of the peanut butters was assessed using a Texture Analyzer (TA-XTplus, Micro Stable System Co., UK) to apply $30 \mathrm{~mm}$ penetration on the peanut butters at a speed of $1 \mathrm{~mm} / \mathrm{s}$ and a trigger force of $5 \mathrm{~g}$. The back-extrusion apparatus was equipped with a locating base plate, a sample container (50 $\mathrm{mm}$ internal diameter), and a compression disc ( $35 \mathrm{~mm}$ diameter). To preciously measure the textural qualities of the peanut butters, samples were placed into the container at the same volume level (75\% full). The exerted force (up and down) was automatically measured. The texture of the peanut butters was explained by the following parameters: firmness ( $\mathrm{g}$ ), cohesiveness $(\mathrm{g})$, consistency $(\mathrm{g} \cdot \mathrm{s})$, and index of viscosity $(\mathrm{g} \cdot \mathrm{s})$. Firmness is defined as the force at the maximum distance of a penetration cycle, while cohesiveness is the maximum negative force (expressed as positive values). Consistency and the index of viscosity are the area of positive and negative zone (expressed as positive values), respectively. Each sample was analysed in duplicate and the average values were calculated for all parameters.

\subsection{Assessment of the rheology of the peanut butters}

The rheological properties of peanut butters were characterized by a controlled stress rheometer (HR-2, TA Instruments, New Castle, USA) armed with a crosshatched plate $(40 \mathrm{~mm}$ diameter, plate geometry with $1 \mathrm{~mm}$ gap). About $2 \mathrm{~g}$ peanut butter was loaded onto the plate for analysis. The rheological properties were detected through two aspects: shear rate sweep and dynamic oscillatory tests. For the shear rate sweep test, the steady state detections were carried out at a shear rate range of $1-300 / s$ after 2 min of conditioning. The flow behaviour was modelled using the Herschel-Bulkley's model (Eq. (2)) (Taghizadeh \& Razavi, 2009). It is generally used to indicate the rheological properties of foods to provide rheological constants of food products.

$\sigma=\sigma_{0}+K \times r^{n}$

Where $\sigma$ stands for shear stress $(\mathrm{Pa}), \sigma_{0}$ stands for yield stress (Pa), Kstands for consistency coefficient $\left(\mathrm{Pa} \cdot \mathrm{S}^{\mathrm{n}}\right), r$ stands for shear rate $\left(\mathrm{S}^{-1}\right)$, and $\mathrm{n}$ stands for flow behaviour index (Zhou, Zhang, Chen, \& Chen, 2017).

The dynamic oscillatory experiment was conducted to collect dynamic rheological behaviours including the storage modulus $\left(G^{\prime}\right)$ and the loss modulus $\left(G^{\prime \prime}\right)$ through frequency sweep. A constant angular frequency $(1 \mathrm{~Hz})$ was used to identify the linear viscoelastic range (LVR) of peanut butter. The frequency was increased from 0.1 to $100 \mathrm{~Hz}$, and all tests were conducted within the LVR. The $G^{\prime}$ and $G^{\prime \prime}$ were modelled as a power function of oscillatory frequency ( $\omega$ ) (Eq. (3), (4)), as generally used for indicating the viscoelastic behaviour of peanut butter, which was used to indicate firmness and viscosity.

$G^{\prime}=a \times \omega^{b}$

$G^{\prime \prime}=c \times \omega^{d}$

The power law coefficients, $a / c\left(\mathrm{kPa} \mathrm{Hz}^{-} \mathrm{b} / \mathrm{d}\right)$, illustrate the amount of $\mathrm{G}^{\prime}$ and $\mathrm{G}^{\prime \prime}$ respectively at a given frequency. The power law exponents, $b / d(\times 100)$, illustrate the slope of the relationships between the modulus and frequency (Liu et al., 2019; Resch \& Daubert, 2002). Each peanut butter sample was analysed in duplicate and the average values were calculated for all parameters.

\subsection{Analysis of the particle size distributions of the peanut butters}

The particle size distributions of the peanut butters were detected by a Malvern 3000 Mastersizer (Malvern Instruments Ltd, Worcerstershire, U.K.) equipped with a sample input cell (Hydro $2000 \mathrm{MU}$ ). Each sample $(0.1 \mathrm{~g})$ was weighed into a $25 \mathrm{~mL}$ test tube and $15 \mathrm{~mL}$ of acetone (Sinopharm Chemical Reagent Co., Ltd, Beijing, China) as the diluter was appended to disperse the sample by a vortex mixer (Scientific Industries, Inc, Bohemia, USA). After that, the diluted sample was placed into the input cell stuffed with $600 \mathrm{~mL}$ deionized water until the obscuration range was within $0.10-0.15$. The obscuration indicates the magnitude of light obscured by the sample as a result of the scattering and absorbing effects. The refractive indexes of acetone and the peanut butter were 1.376 and 1.500 , respectively (Norazatul Hanim et al., 2016). The acquired data were analysed using the Malvern software (Malvern Instruments Ltd, Worcerstershire, U.K.) according to the Mie Scattering theory. Each sample was analysed three times and the average values were calculated for all diameter parameters. The polydispersity value indicating the particle size was specified in Eq. (5).

Polydispersity $=(D 90-D 10) / D 50$ 
where D10, D50, and D90 are the average value of diameter which falls below 10th, 50th, and 90th percentile of particle size distributions.

\subsection{Data analysis}

Univariate comparisons were carried out on the data of the peanut kernels and peanut butters to identify statistical features, including average, standard deviation (SD), minimum (min), maximum (max), first quartile (Q1), and third quartile (Q3) values. Principal component analysis (PCA) was used to explore the relationships of average values of quality traits of peanut varieties and the key characteristics of peanut butters. Unsupervised clustering was explored using K-means procedures. The distance between each sample and the nearest mean was determined to obtain the different groups. Kruskal-Wallis tests were applied to assess if there were any significant differences between different peanut butter groups because the data were not normally distributed as shown by the Shapiro-Wilk tests. Pairwise comparisons were implemented by the Mann-Whitney U tests to evaluate differences in various traits of peanut butters between different groups. Correlation analysis was used to evaluate the strength of the relationships between univariate qualities of the peanuts and univariate results and PCA outcomes of the peanut butters. R 4.0.1 statistical software (R Foundation for Statistical Computing, Austria) was used for all calculations.

\section{Results and discussion}

\subsection{The traits of the peanut varieties: univariate comparisons}

The quality traits of forty peanut varieties are shown in Table 1 . The dimensions of the peanut kernels varied between 14.4 and $20.5 \mathrm{~mm}$ (length) and 8.5-11.6 mm (width). The weight of the peanut kernels was mainly determined by seed size (as represented by its dimensions),

Table 1

The univariate descriptive analysis of the quality traits of all the peanut kernel varieties $(n=40)$ and their related peanut butters.

\begin{tabular}{|c|c|c|c|c|c|c|c|}
\hline Samples & Traits & Average & Min & Max & SD & Q1 & Q3 \\
\hline \multirow[t]{26}{*}{ Peanut kernels } & Length (mm) & 17.5 & 14.4 & 20.5 & 1.7 & 16.0 & 18.7 \\
\hline & Width $(\mathrm{mm})$ & 10.2 & 8.5 & 11.6 & 0.8 & 9.7 & 10.7 \\
\hline & Weight (100 kernels, g) & 73.6 & 43.4 & 101.7 & 14.7 & 61.3 & 86.1 \\
\hline & Fat $(g / 100 g)$ & 48.3 & 42.6 & 52.9 & 3.0 & 46.1 & 50.7 \\
\hline & Protein $(\mathrm{g} / 100 \mathrm{~g})$ & 23.6 & 19.3 & 26.4 & 1.6 & 22.6 & 24.9 \\
\hline & Sucrose $(\mathrm{g} / 100 \mathrm{~g})$ & 4.8 & 3.3 & 7.9 & 1.0 & 4.1 & 5.5 \\
\hline & Glu $(g / 100 \mathrm{~g})$ & 5.03 & 3.42 & 6.01 & 0.53 & 4.79 & 5.39 \\
\hline & Asp (g/100 g) & 3.08 & 2.27 & 3.84 & 0.35 & 2.88 & 3.27 \\
\hline & $\operatorname{Arg}(g / 100 \mathrm{~g})$ & 2.99 & 1.89 & 3.56 & 0.35 & 2.76 & 3.25 \\
\hline & Leu $(g / 100 \mathrm{~g})$ & 1.77 & 1.35 & 2.12 & 0.20 & 1.63 & 1.90 \\
\hline & Gly (g/100 g) & 1.54 & 1.09 & 1.99 & 0.19 & 1.47 & 1.64 \\
\hline & $\operatorname{Ser}(g / 100 g)$ & 1.28 & 0.89 & 1.94 & 0.21 & 1.16 & 1.39 \\
\hline & Thr $(g / 100 \mathrm{~g})$ & 0.64 & 0.38 & 0.79 & 0.08 & 0.58 & 0.70 \\
\hline & Cys (g/100 g) & 0.37 & 0.28 & 0.60 & 0.08 & 0.33 & 0.41 \\
\hline & Phe $(\mathrm{g} / 100 \mathrm{~g})$ & 1.29 & 0.84 & 1.83 & 0.17 & 1.21 & 1.37 \\
\hline & Ala (g/100 g) & 0.98 & 0.82 & 1.11 & 0.08 & 0.93 & 1.05 \\
\hline & Met $(\mathrm{g} / 100 \mathrm{~g})$ & 0.32 & 0.19 & 0.46 & 0.07 & 0.28 & 0.37 \\
\hline & Val (g/100 g) & 1.00 & 0.63 & 1.34 & 0.17 & 0.87 & 1.11 \\
\hline & Pro $(g / 100 \mathrm{~g})$ & 1.01 & 0.71 & 1.53 & 0.17 & 0.88 & 1.07 \\
\hline & Tyr (g/100 g) & 1.00 & 0.63 & 1.25 & 0.16 & 0.87 & 1.11 \\
\hline & Lys (g/100 g) & 0.98 & 0.77 & 1.20 & 0.09 & 0.92 & 1.03 \\
\hline & His $(\mathrm{g} / 100 \mathrm{~g})$ & 0.55 & 0.40 & 0.66 & 0.06 & 0.51 & 0.60 \\
\hline & Ile $(\mathrm{g} / 100 \mathrm{~g})$ & 0.84 & 0.58 & 1.31 & 0.16 & 0.75 & 0.90 \\
\hline & Oleic acid $(\mathrm{g} / 100 \mathrm{~g})$ & 25.56 & 14.82 & 43.83 & 9.68 & 17.86 & 36.48 \\
\hline & Linoleic acid (g/100 g) & 12.91 & 1.24 & 23.61 & 7.61 & 2.18 & 18.46 \\
\hline & Palmitic acid (g/100 g) & 4.75 & 2.20 & 7.02 & 1.48 & 2.98 & 6.01 \\
\hline \multirow[t]{25}{*}{ Peanut butters } & 2,5-Dimethylpyrazine (mg/kg) & 5.10 & 2.08 & 11.00 & 2.03 & 3.41 & 6.17 \\
\hline & 2,3,5-Trimethylpyrazine $(\mathrm{mg} / \mathrm{kg})$ & 2.17 & 0.62 & 5.46 & 0.99 & 1.40 & 2.62 \\
\hline & 3-Ethyl-2,5-dimethylpyrazine $(\mathrm{mg} / \mathrm{kg})$ & 1.41 & 0.57 & 3.66 & 0.66 & 0.91 & 1.79 \\
\hline & 2-Acetylpyrrole $(\mathrm{mg} / \mathrm{kg})$ & 0.91 & 0.23 & 1.83 & 0.39 & 0.74 & 1.12 \\
\hline & Furaneol $(\mathrm{mg} / \mathrm{kg})$ & 1.29 & 0.15 & 2.89 & 0.73 & 0.59 & 1.78 \\
\hline & 2-Methoxy-4-vinylphenol (mg/kg) & 2.03 & 0.39 & 4.77 & 0.86 & 1.45 & 2.39 \\
\hline & Dibutyl phthalate $(\mathrm{mg} / \mathrm{kg})$ & 0.78 & 0.08 & 3.93 & 0.87 & 0.27 & 0.95 \\
\hline & $L^{*}$ & 53.3 & 34.8 & 64.1 & 6.2 & 50.6 & 56.6 \\
\hline & $a^{*}$ & 9.6 & 3.5 & 13.5 & 2.7 & 8.8 & 11.8 \\
\hline & $b^{*}$ & 27.0 & 16.6 & 28.8 & 2.3 & 26.9 & 28.3 \\
\hline & Firmness (g) & 41.2 & 24.4 & 124.5 & 15.7 & 34.3 & 46.2 \\
\hline & Consistency $(\mathrm{g} \cdot \mathrm{s})$ & 1058.0 & 646.7 & 3248.1 & 414.4 & 849.5 & 1203.7 \\
\hline & Cohesiveness $(\mathrm{g})$ & 22.1 & 12.2 & 97.2 & 13.3 & 16.7 & 24.5 \\
\hline & Index of viscosity $(\mathrm{g} \cdot \mathrm{s})$ & 389.5 & 63.1 & 2240.0 & 349.8 & 213.4 & 514.9 \\
\hline & Yield stress $(\mathrm{Pa})$ & 9.13 & 2.79 & 26.28 & 4.14 & 6.21 & 11.20 \\
\hline & Consistency coefficient (K, Pa.sn) & 5.24 & 2.19 & 22.74 & 3.57 & 3.28 & 5.57 \\
\hline & Flow behaviour index (n) & 0.82 & 0.65 & 0.88 & 0.05 & 0.80 & 0.86 \\
\hline & $G^{\prime}-\mathrm{a}\left(\mathrm{Pa} \cdot \mathrm{s}^{\mathrm{b}}\right)$ & 47.81 & 18.96 & 92.40 & 18.73 & 31.76 & 59.55 \\
\hline & $G^{\prime}-\mathrm{b} \times 100$ & 18.35 & 12.85 & 28.89 & 3.45 & 15.83 & 20.23 \\
\hline & $G^{\prime \prime}-\mathrm{c}\left(\mathrm{Pa} \cdot \mathrm{s}^{\mathrm{d}}\right)$ & 37.63 & 11.01 & 61.32 & 13.91 & 24.46 & 48.85 \\
\hline & $C^{\prime \prime}-\mathrm{d} \times 100$ & 34.10 & 21.45 & 46.08 & 4.53 & 31.37 & 36.60 \\
\hline & $\mathrm{D} 10(\mu \mathrm{m})$ & 8.14 & 5.30 & 10.83 & 1.32 & 7.23 & 8.68 \\
\hline & $\mathrm{D} 50(\mu \mathrm{m})$ & 48.70 & 28.06 & 70.26 & 12.91 & 39.58 & 61.15 \\
\hline & $\mathrm{D} 90(\mu \mathrm{m})$ & 151.95 & 89.25 & 192 & 21.60 & 141.75 & 163.40 \\
\hline & Polydispersity & 3.17 & 1.54 & 5.72 & 1.00 & 2.30 & 3.84 \\
\hline
\end{tabular}

(Ala) Alanine; (Arg) Arginine; (Asp) Aspartic acid; Cys (Cysteine); (His) Histidine; (Ile) Isoleucine; (Glu) Glutamic acid; (Gly) Glycine; (Leu) Leucine; (Lys) Lysine; (Max) maximum; (Met) Methionine; (Min) Minimum; (O/L) Oleic acid/Linoleic acid; (Phe) Phenylalanine; (Pro) Proline; (Q1) Quartile 1; (Q3) Quartile 3; (Ser) Serine; (SD) Standard deviation; (Thr) Threonine; (Tyr) Tyrosine; (Val) Valine. 
which meant that smaller seed size varieties had a lower weight, and vice versa (Zhang et al., 2019). For example, the weight of SH8 (length $14.4 \pm 1.3 \mathrm{~mm}$ and width $8.5 \pm 0.5 \mathrm{~mm}$ ) was $43.3 \pm 1.2 \mathrm{~g}$, while the weight of WH8 (length $19.6 \pm 1.0 \mathrm{~mm}$ and width $11.3 \pm 0.5 \mathrm{~mm}$ ) was $101.7 \pm 2.3 \mathrm{~g}$.

The range of fat and protein in the peanut kernels were $42.6-52.9 \mathrm{~g} /$ $100 \mathrm{~g}$ and 19.3-26.4 g/100 g, respectively, which was similar to previously reported results (Gong et al., 2018; Nayak et al., 2020; Wang, 2016). The content of sucrose ranged from 3.3 to $7.9 \mathrm{~g} / 100 \mathrm{~g}$, which was consistent with the previous studies (Bishi et al., 2013; Wang, 2018). Among all varieties, the sucrose content in JHT1 was up to $7.9 \pm 0.2$ $\mathrm{g} / 100 \mathrm{~g}$. Among the measured amino acids, Arginine (Arg), Aspartic acid (Asp), and Glutamic acid (Glu) were the three most abundant compounds and similar results have been reported in previous research (Klevorn, Dean, \& Johanningsmeier, 2019; Wang, Wang, Liu, Liu, \& Du, 2013). In this study, twelve high oleic acid peanut varieties (DF06, HY661, HY917, HY962, HY963, JH16, JH18, JH19, WH25, YH37, YH65, and YH76) were used in addition to regular varieties since they, as raw materials for manufacture can extend the shelf life of final products (Gong et al., 2018) and boost a product's nutritional quality (Zhao, Shi, Wang, \& Zhou, 2019a). Therefore, a considerable variation in fatty acids composition (oleic acid, 14.82-43.83 g/100 g; linoleic acid $1.24-23.61 \mathrm{~g} / 100 \mathrm{~g}$ ) was noted. The wide variation of the quality traits suggested an abundant diversity among the forty peanut varieties.

\subsection{The traits of the peanut varieties: multivariate comparisons}

The PCA biplot (Fig. 2) shows that the samples were clustered in three groups based on the quality traits of peanut varieties in Table 1. The sum of PC1 and PC2 was 48\%, accounting for half of the total variation. The "contrib" values represent the contributions of these traits on explaining the variations retained by the first two PCs. Among them, amino acids such as Alanine (Ala), Glutamic acid (Glu), and Lysine (Lys) and fatty acids such as oleic acid had the greatest contributions to PC1 and PC2, respectively. According to the K-means results, all high oleic acid peanut varieties (cluster 2) distributed in the negative half along PC2, while the regular peanut varieties (cluster 1 and 3) were located in the opposite direction because oleic acid had a negative correlation with palmitic acid and linoleic acid in peanut samples (Yu, Liu, Wang, \& van Ruth, 2020). The regular peanut varieties (cluster 1 and 3) were separated according to the contributions of amino acids and protein content along PC1. Cluster 3 had closer association with amino acids than cluster 1, especially for Ala, Arginine (Arg), Glu, Leucine (Leu), and Lys. In contrast to above variables, the fat and physical characteristics of the peanut varieties were not the main contributions for PC1 and PC2. This was mainly because there were no remarkable differences in fat content and physical characteristics between the varieties.

\subsection{The traits of the peanut butters: univariate comparisons}

All parameters of the studied peanut butters are also shown in Table 1 . The unique aroma is the key quality of peanut butter. The attractive aroma of peanut butter is formed through reactions such as the Maillard reaction during the peanut roasting and grinding processes (Starowicz \& Zieliński, 2019; Wang et al., 2017d). About 41 volatile compounds, including pyrazines, furans, esters, pyridines, and aldehydes, were detected for each peanut butter (Appendix supplement 2). As shown in Fig. 3a, pyrazines and furans had obvious quantitative advantages than other compounds in the peanut butters, which was similar to the previous research (Lou et al., 2009). The link lines between the volatile compounds and the peanut butters indicate that the contents of volatile compounds exceeded $5 \mathrm{mg} / \mathrm{kg}$ in Fig. 3a. The thicker the line, the higher the contents. The volatile compounds varied greatly between different varieties. Among them, HY20, HY25, JH16, JH18, and LH11 presented higher concentrations of volatile compounds than other varieties.

It is likely that the intensity of volatile compounds was not only related to the concentrations of compounds, but also related to the odour threshold (OT) (Tamura et al., 2010). Therefore, both the concentration and OT should be considered to identify the compounds that commonly make the most contributions to the overall aroma of the peanut butters. Normally, the compounds are regarded as the effective compounds when the ratio of concentration/OT value is over one. Among them, pyrazines, usually with nutty and roast aromas, were the main volatile compounds of peanut butter, accounting for about $30 \%$ of the total volatile concentrations. Many studies have reported that pyrazines are the primary volatiles of peanut products (Baker et al., 2003; Li \& Hou, 2018). In line with this, 2,5-dimethylpyrazine $(\mathrm{RI}=915), 2,3,5$-trimethylpyrazine (RI = 999), and 3-ethyl-2,5-dimethylpyrazine ( $\mathrm{RI}=$ 1041) were the top three pyrazines detected in this study. As shown in Table 1, the average value of 2,5-dimethylpyrazine in peanut butters was $5.10 \pm 2.03 \mathrm{mg} / \mathrm{kg}$ with the OT in vegetable oil $2.6 \mathrm{mg} / \mathrm{kg}$ (van Gemert, 2011); the ratio of concentration/OT value $\approx 2$. The average value of 2,3,5-trimethylpyrazine was $2.17 \pm 0.99 \mathrm{mg} / \mathrm{kg}$ and the OT in vegetable oil was $0.29 \mathrm{mg} / \mathrm{kg}$ (van Gemert, 2011); ratio of concentration/OT value $\approx 7$, while the average value of 3-ethyl-2,5-dimethylpyrazine $(\mathrm{RI}=1041)$ was $1.41 \pm 0.66 \mathrm{mg} / \mathrm{kg}$ and the OT in vegetable oil was $0.024 \mathrm{mg} / \mathrm{kg}$ (van Gemert, 2011); the ratio of concentration/OT

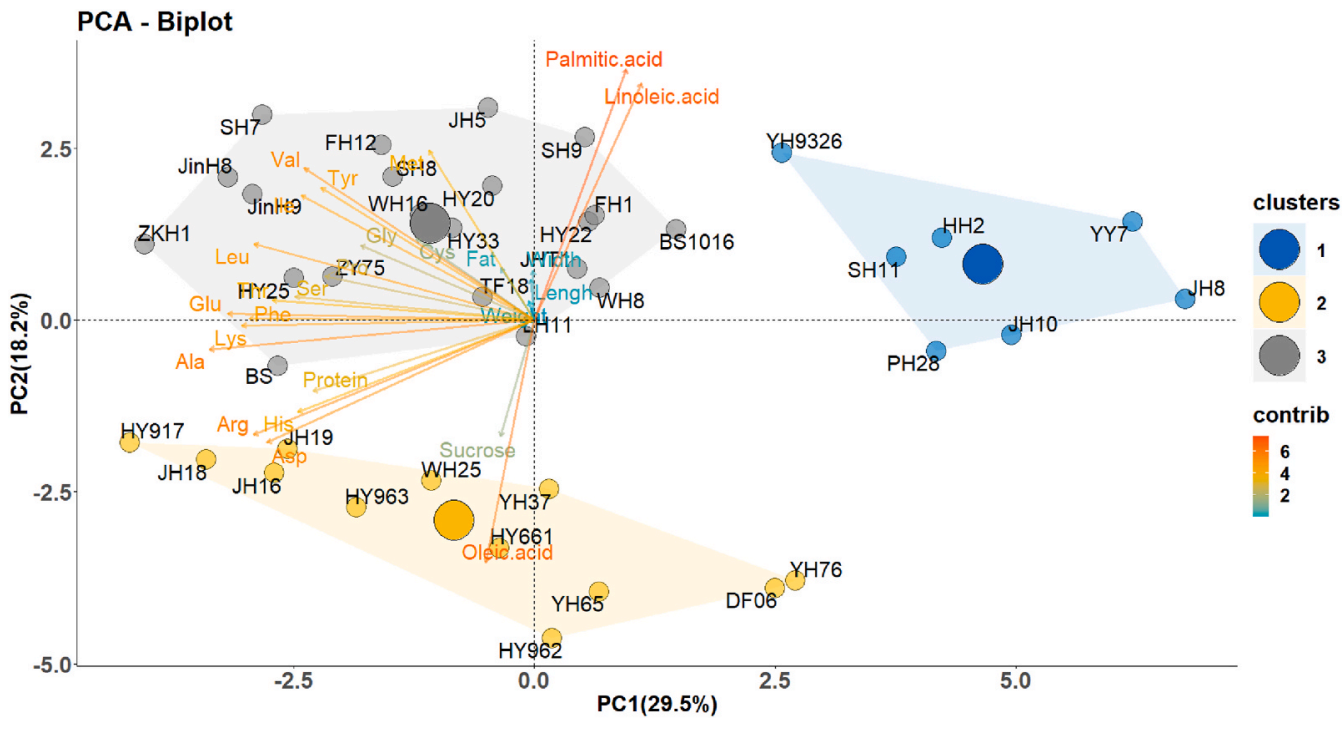

Fig. 2. The principal component analysis (PCA) biplot of different peanut varieties $(n=40)$. The different colored polygons indicate the different sample clusters and the arrows indicate the contributions of the quality traits. (Ala) Alanine; (Arg) Arginine; (Asp) Aspartic acid; (Cys) Cysteine; (contrib) Contribution; (His) Histidine; (Ile) Isoleucine; (Glu) Glutamic acid; (Gly) Glycine; (Leu) Leucine; (Lys) Lysine; (Met) Methionine; (Phe) Phenylalanine; (Pro) Proline; (Ser) Serine; (Thr) Threonine; (Tyr) Tyrosine; (Val) Valine. 


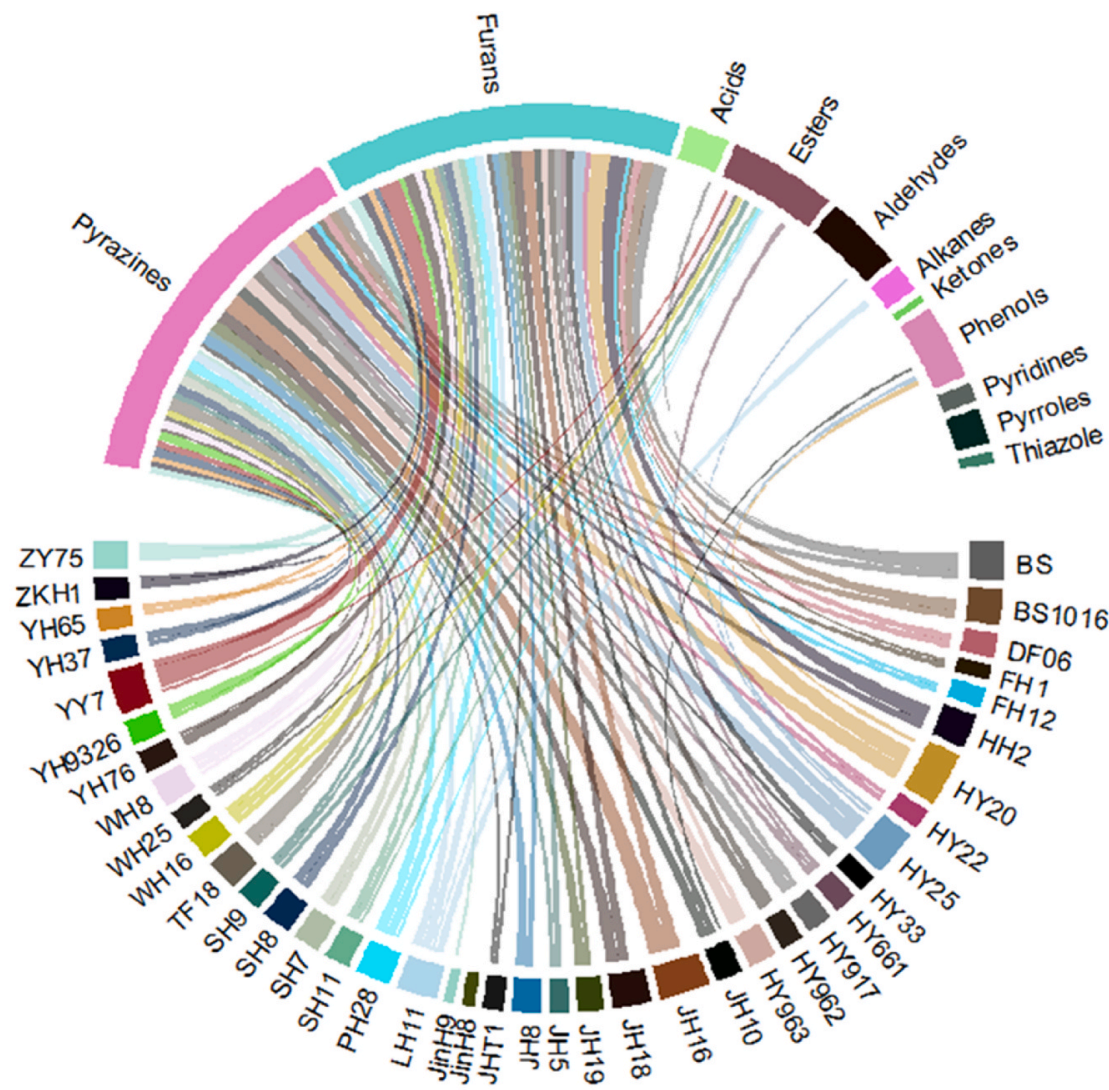

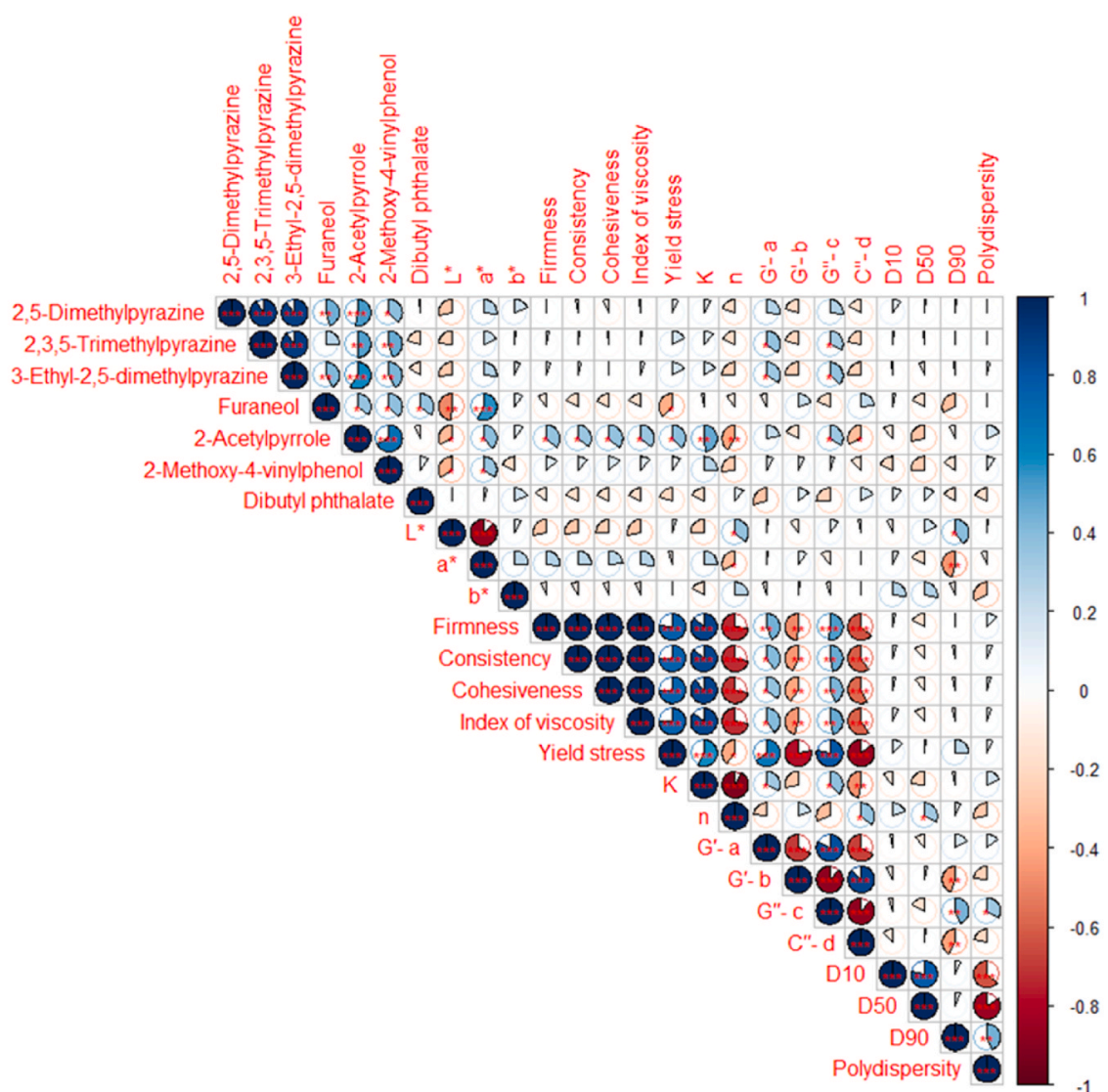

Fig. 3. The (a) volatile compounds of the different peanut butters (the link lines indicate that the contents of volatile compounds that exceeded 5 $\mathrm{mg} / \mathrm{kg}$ ), and the (b) correlation analysis of the qualities of the peanut butters. The positive and negative correlation coefficients (r) are colored blue and red, respectively. The fraction of the circles stands for the correlation coefficient and full fraction means $\mathrm{r}=1$. ( ${ }^{*} P<0.05$, ** $P<0.01$, *** $P<0.001$ ). (For interpretation of the references to colour in this figure legend, the reader is referred to the Web version of this article.) 
value $\approx 59.2,5$-Dimethylpyrazine and 2,3,5-trimethylpyrazine not only have a strong correlation with roasted peanut aroma (Baker et al., 2003; S.; Wang et al., 2017a), but 2,5-Dimethylpyrazine can also be used as the best predictor of roasted aroma.

Apart from the above-mentioned pyrazines as effective compounds, 2 -acetylpyrrole $(\mathrm{RI}=1564)$ and furaneol $(\mathrm{RI}=1629)$, also known as typical Maillard reaction products, have been stated to augment the roasty aroma of peanut oil and nut products (Arsa \& Theerakulkait, 2018; Liu et al., 2011; van Gemert, 2011). The average value of 2-acetylpyrrole was $0.91 \pm 0.39 \mathrm{mg} / \mathrm{kg}$ and the OT in the source was 0.019 $\mathrm{mg} / \mathrm{kg}$ (Lin et al., 2019); the ratio of concentration/OT value $\approx 48$. In comparison, the average value of furaneol was $1.29 \pm 0.73 \mathrm{mg} / \mathrm{kg}$ and the OT in sunflower oil was $0.025-0.05 \mathrm{mg} / \mathrm{kg}$ (van Gemert, 2011); the ratio of concentration/OT value $\approx 52$. 2-Methoxy-4-vinylphenol $(\mathrm{RI}=$ 1787 ) is a naturally present phenolic compound which can be found in peanuts and clove (Jeong \& Jeong, 2010) and commonly exist in peanut oil (Hu et al., 2014). The average value of 2-methoxy-4-vinylphenol was $2.03 \pm 0.86 \mathrm{mg} / \mathrm{kg}$ and the OT in the oil was $0.05 \mathrm{mg} / \mathrm{kg}$ (van Gemert, 2011 ); the ratio of concentration/OT value $\approx 40$. In addition, dibutyl phthalate $(\mathrm{RI}=2290)$ existed in roasting products (Akkad, Kharraz, Han, House, \& Curtis, 2019), where the average value was $0.78 \pm 0.87$ $\mathrm{mg} / \mathrm{kg}$ and the OT in the air was $0.26 \mathrm{mg} / \mathrm{L}$ (van Gemert, 2011); the ratio of concentration/OT value $\approx 3$.

The correlation analysis, as shown in Fig. 3b, shows that there were significantly positive correlations $(P<0.05)$ between the seven volatile compounds except for dibutyl phthalate, which meant that peanut butter with aroma advantage had a higher content of the previously discussed aroma compounds. Among them, 2-acetylpyrrole was significantly positively correlated with pyrazines $(P<0.05)$. This was because 2 -acetylpyrrole could be generated by the reaction of sucrose with other substances (Maarse, 2017). Furaneol and pyrazines are both aroma substances produced by peanuts during roasting (Liu et al., 2017). Therefore, there was a significantly positive correlation between them $(P<0.05)$.

The colour is the most intuitive impression of peanut butter. The average colour values of the peanut butters were $53.3 \pm 6.2\left(\mathrm{~L}^{*}\right), 9.6 \pm$ $2.7\left(\mathrm{a}^{*}\right)$, and $27.0 \pm 2.3\left(\mathrm{~b}^{*}\right)$, respectively, which were also similar to the previous results (L*, 56; a*, 10; b*, 26) (Ha, Kim, Ryu, \& Kang, 2013; Sanders et al., 2014). Among all peanut butters, JinH8 had a bright white colour with the highest $L^{*}(64.1 \pm 0.1)$ and the lowest $a *(3.5 \pm$ $0.1)$ values. In comparison, ZY75 had a dark puce colour and the lowest $L^{*}(34.8 \pm 0.1)$, the highest $a^{*}(12.8 \pm 0.1)$, and the lowest $b *(16.6 \pm$ 0.1 ) values. The variance of colour between different varieties could be huge due to the qualities of raw materials under the same roasting conditions. More pictures and details are provided as supplementary material in Appendix supplement 1 and 3. There was a significantly negative relationship between $L^{*}$ and $a^{*}(P<0.05)$ in Fig. $3 \mathrm{~b}$. In other words, an increase in $a^{*}$ value increased the red value, resulting in a darker colour. In addition, $L^{*}$ had the significantly opposite trend with volatile compounds formed through reactions such as the Maillard reaction, especially 2-acetylpyrrole, furaneol, and 2-methoxy-4-vinylphenol $(P<0.05)$. Meanwhile, a higher roasting level produced a darker peanut butter (low $L^{*}$ value). Therefore, one can assume that peanut butters with lower $L^{*}$ values have higher concentrations of the above-mentioned volatiles.

The average texture values of the peanut butters were as follows: firmness, $41.2 \pm 15.7 \mathrm{~g}$; consistency, $1058.0 \pm 414.4 \mathrm{~g} \mathrm{~s}$; cohesiveness, $22.1 \pm 13.3 \mathrm{~g}$; index of viscosity, $389.5 \pm 349.8 \mathrm{~g}$ s. The texture characteristics of different peanut butters were significantly varied (Supplementary material, Appendix supplement 3). For example, JHT1 had the highest texture values (firmness, $124.5 \pm 1.1 \mathrm{~g}$; consistency, 3248.1 $\pm 34.6 \mathrm{~g} \mathrm{~s}$; cohesiveness, $97.2 \pm 1.2 \mathrm{~g}$; index of viscosity, $2240.0 \pm 4.6 \mathrm{~g}$ s), while YH76 had the lowest texture values (firmness, $24.4 \pm 0.2 \mathrm{~g}$; consistency, $646.7 \pm 4.7 \mathrm{~g}$ s; cohesiveness, $12.2 \pm 0.1 \mathrm{~g}$; index of viscosity, $63.1 \pm 2.8 \mathrm{~g} \mathrm{~s}$ ). Firmness and consistency are reported to be related to the hardness of peanut butter, which are the sensory attributes evaluated at the initial and tongue-palate compression of oral processing (Koc, Vinyard, Essick, \& Foegeding, 2013; Nasaruddin, Chin, \& Yusof, 2012). Cohesiveness and the index of viscosity are the tendency of peanut butter to cohere or stick together, while these properties also correlate with the slipperiness and adhesiveness of peanut butter (Koc et al., 2013). In the oral cavity, it is the speed at which peanut butter spreads on the tongue. The greater the cohesion, the slower the diffusion (Arrieta-Escobar, Bernardo, Orjuela, Camargo, \& Morel, 2019). Therefore, the diversity levels of texture qualities were from YH76 to JHT1, which provides a basis reference for enterprises to select varieties. The correlation analysis (Fig. 3b) shows that firmness and cohesiveness were significantly correlated $(P<0.05)$ with consistency and the index of viscosity. Hence, firmness and cohesiveness were chosen as the main texture characteristics for further analysis.

According to the results of the shear rate sweep, the viscosity of peanut butters decreased as the shear rate increased, reflecting that peanut butter is a typical non-Newtonian fluid with pseudoplastic characteristics. The relationship between shear stress and shear rate could be calculated by Herschel-Bulkley. The fitting coefficients of all peanut butters were above 0.99 . The models have three important parameters: yield stress $\left(\sigma_{0}, \mathrm{~Pa}\right), \mathrm{K}$ (consistency coefficient, Pa.sn), and $\mathrm{n}$ (flow behavior index). The yield stress is the minimum shear stress needed to break the peanut butter's internal structure in order to initiate peanut butter flow (Augusto, Cristianini, \& Ibarz, 2012). If stress value is under the yield stress, peanut butter performs like an elastic solid. In contrast, it performs like a viscous liquid (Augusto et al., 2012). The average value of yield stress for the peanut butters was $9.13 \pm 4.09 \mathrm{~Pa}$. The difference among different varieties were obvious. JHT1 had the largest yield stress value $(26.28 \pm 2.53 \mathrm{~Pa})$, making it the most difficult peanut butter to flow. On the contrary, the yield stress of YH76 was only $2.79 \pm 0.11 \mathrm{~Pa}$, which made it the easiest to start flowing. $\mathrm{K}$ is related to the energy to maintain flow and is directly proportional to the viscosity of the sample (Suhui, Xuede, Yuxiang, Jingyuan, \& Guozhan, 2019). The average value of $\mathrm{K}$ was $5.24 \pm 3.52 \mathrm{~Pa} \cdot \mathrm{sn}$. Among all peanut butters, JHT1 had the highest $\mathrm{K}$ value $(22.74 \pm 1.52 \mathrm{~Pa} \cdot \mathrm{sn})$ and resultingly the highest viscosity. The $\mathrm{n}$ value reflects flow behavior of peanut butter. The range of $n$ value was from 0.65 to 0.88 which was less than one in all formulations showing non-Newtonian shear thinning behavior, which was similar to the previous results of shear rate sweep. For dynamic characteristics, storage modulus $\left(G^{\prime}\right)$ presents the power reserved during every cycle of dynamic oscillation reflecting the elastic characteristics of peanut butter, while loss modulus $\left(G^{\prime \prime}\right)$ exposits the power dissipation in relation to the viscous characteristics (X. Wang et al., 2017b). All peanut butters showed gel characteristics because of $G^{\prime}>G^{\prime \prime}$ at all frequencies (Liu et al., 2019). The $G^{\prime}$-a and $G^{\prime \prime}$-c of Power law model $\left(\mathrm{R}^{2}>0.99\right)$ indicate the amount of $G^{\prime}$ and $G^{\prime \prime}$ at a given frequency (Resch \& Daubert, 2002). The consistently higher $G^{\prime}$-a than $G^{\prime \prime}$-c represented the aforesaid greater $G^{\prime}$ than $G^{\prime \prime}$ (Norazatul Hanim et al., 2016). The $G^{\prime}$-b and $G^{\prime \prime}$-d reflect the magnitude of dependence of $\mathrm{G}^{\prime}$ and $\mathrm{G}^{\prime \prime}$ on frequency (Norazatul Hanim et al., 2016). The $G^{\prime}$-b of all samples ranged from 12.85 to 28.89, which signified that peanut butter was a weak physical gel product (Bayod, Willers, \& Tornberg, 2008; Tunick, 2011). It could be found that n, $G^{\prime}$-b, and $G^{\prime \prime}$-d reflected the same properties for all peanut butters, while Yield stress, $\mathrm{K}, G^{\prime}$-a, and $G^{\prime \prime}$-c varied greatly between different peanut butters.

According to Eq. (4), the polydispersity reflects the particle size distributions, which means the higher the value, the wider the particle size distributions. The average polydispersity value of the peanut butters was $3.17 \pm 0.99$, which is similar to that of commercial peanut butter ( $3.36 \pm 0.08)$ (Norazatul Hanim et al., 2016). Among all peanut butters, FH12 had the lowest polydispersity value (1.54), while JinH8 had the highest value (5.72). With the decrease in particle size, the particle-particle interaction strength also decreases affecting the rheological characteristics and the mouthfeel of peanut butter in oral processing (Norazatul Hanim et al., 2016; Stokes, Boehm, \& Baier, 2013). According to Fig. 3b, the polydispersity had a significantly positive 
relationship with $G^{\prime \prime}$-c $(P<0.05)$. This means that the decrease in particle size led to a decrease in viscosity.

\subsection{The traits of the peanut butters: multivariate comparison}

K-means clustering combined with PCA was applied to elaborate the relationships between the different peanut butters. To balance the weights of different variables, raw data was auto-scaled before PCA. JHT1 with extreme values of textural and rheological properties was removed because it was located outside the ellipse of the Hotelling's $\mathrm{T}^{2}$ (0.5\%) (Yu, Liu, Wang, \& van Ruth, 2020). An overview of the differences between the peanut butters relating to all tested parameters is shown in Fig. 4a. The first two PCs of the model explained $52 \%$ of the total variance with a contribution of $32 \%$ from PC1. In addition to dibutyl phthalate, $\mathrm{b}^{*}$, and polydispersity, other variables mainly contributed to PC1 and PC2. Among them, pyrazines, 2-acetylpyrrole, firmness, and $\mathrm{K}$ had the greatest contributions to PC1, while furaneol, yield stress, a*, $\mathrm{L}^{*}$ and $G^{\prime \prime}-\mathrm{c}$ had the greatest contributions to PC2. According to the K-means results, three clusters of peanut butters could be identified on the PCA biplot. Cluster 1 (HY25, JH16, and HY963 etc.) grouped on the right of the PCA biplot (the opposite direction of PC1). Most parameters had the same direction with this group, such as volatile compounds, texture, and rheological qualities. Cluster 2 (SH9, YH65, and JinH8 etc.) located on the top left of the PCA biplot (the negative direction of PC1 and the positive direction of PC2). This group presented a positive relationship with $L^{*}$ and negative relationship with volatile compounds. Cluster 3 (BS1016, HY33, and YY7 etc.), situated on the bottom left of the PCA biplot. This cluster associated positively with dibutyl phthalate and negatively with texture and rheological qualities.

The results of the different parameters in different peanut butter groups are shown in Fig. 4b. Most parameters had significant differences between different groups except for 2-methoxy-4-vinylphenol, dibutyl phthalate, $b^{*}$, and polydispersity. Each group had inherent characteristics. Specifically, group 1 had significantly higher contents of most volatile compounds than the other groups, especially pyrazines $(P<$ 0.05). Group 2 was significantly different from the other two groups for colour ( $\mathrm{L}^{*}$ and $\mathrm{a}^{*}$ values) $(P<0.05)$. The values for firmness and cohesiveness of group 1 and group 2 were significantly higher than that of group 3. Similar results could also be found for rheology $(P<0.05)$. In summary, group 1 had the highest pyrazine contents, the highest values of texture and rheology qualities, and a moderate level of colour.

\subsection{Relationships between peanut varieties and peanut butters}

The correlation analysis results of the quality traits of the peanut varieties versus all parameters of the peanut butters are shown in Fig. 5a. In terms of the effects of the raw materials, the texture, rheology, and polydispersity were generally bracketed, mainly reflecting the internal structure of peanut butter, while the colour and aroma compounds were correspondingly clustered together. Specifically, sucrose had a significantly positive correlation with the texture (firmness and cohesiveness) and the rheology (yield stress, $\mathrm{K}, G^{\prime}$-a, and $G^{\prime \prime}$-c) of the peanut butters. The Pearson correlation coefficient $(\mathrm{R})$ index between sucrose and the above-mentioned parameters were: $\mathrm{R}_{\text {firmness }}(0.60, P<0.05), \mathrm{R}_{\text {co- }}$ hensiveness $(0.58, P<0.05), \mathrm{R}_{\text {yield stress }}(0.49, P<0.05), \mathrm{R}_{\mathrm{K}}(0.56, P<$ $0.05), \mathrm{R}_{G^{\prime}-\mathrm{a}}(0.36, P<0.05)$, and $\mathrm{R}_{G^{\prime \prime}-\mathrm{c}}(0.47, P<0.05)$ respectively. This could be since sucrose is known to lead to an increase in the macromolecular entanglement (Mathlouthi \& Reiser, 2012; Wang et al., 2009). As a result, the corresponding $\mathrm{R}$ indexes of texture and rheology were increased. In addition, the peanut varieties with higher sucrose contents always had a lower fat content and a higher protein content (Bishi et al., 2013). Importantly, the fat content had a significantly negative relationship with the texture and rheological characteristics such as $\mathrm{R}_{\text {firmness }}$ $(-0.39, P<0.05)$, while the protein content had a significantly positive relationship with these parameters such as $\mathrm{R}_{\text {firmness }}(0.32, P<0.05)$. This is because the continuous fat phase acts as a "lubricant" in the suspension system of peanut butter, while the macromolecules like protein are distributed among it (Citerne, Pierna, \& Moan, 2001; Mohd Rozalli, Chin, Yusof, \& Mahyudin, 2016). Once the fat phase is reduced or the macromolecular substance is increased, the viscosity will increase. Meanwhile, protein as the controlling trait for a stronger gel network makes the samples firmer (Nguyen, Kravchuk, Bhandari, \& Prakash, 2017). Among the measured amino acids, proline (Pro) and Cys were significantly positively correlated with the texture and rheological characteristics. The $\mathrm{R}$ indexs between Pro and the following parameters were: $\mathrm{R}_{\text {firmness }}(0.55, P<0.05), \mathrm{R}_{\text {cohensiveness }}(0.54, P<0.05)$, and $\mathrm{R}_{\text {yield }}$ stress $(0.44, P<0.05)$. Similarly, Cys was postively correlated with the following parameters: $\mathrm{R}_{\text {firmness }}(0.34, P<0.05)$ and $\mathrm{R}_{\text {cohensiveness }}(0.37, P$ $<0.05)$. The reason is that Pro can enhance the hydrophobicity of the internal structure of protein to improve the stability (Levitt, 1978), while Cys can form disulfide bonds (Gudmundsson, 2002). All of these traits could increase the stability of the protein space structure, resulting in the strength of the system.

Amino acids (nitrogen supply) and saccharides (carbon sources) are two important precursor substances known to contribute to the formation of pyrazines (Hui et al., 2010). For instanse, Ser decomposition products could react with sucrose to form pyrazines (Hui et al., 2010). Ser had a significantly positive relationship with 2,5-dimethylprazine and 3-ethyl-2,5-dimethylpyrazine $(P<0.05)$ (Fig. 5a). Meanwhile, Ala, histidine (His), and Leu can react with monosaccharides to produce pyrazines as well (Hui et al., 2010). Therefore, these amino acids likely had a positive contribution to the formation of pyrazines in the peanuts. As a nitrogen-containing heterocyclic compounds, a higher concentration of 2-acetylpyrrole have been observed with the increase in sucrose content (Saputro, Van de Walle, Hinneh, Van Durme, \& Dewettinck, 2018). Correspondingly, the relationship between 2-acetylpyrrole and sucrose was significantly positive $(0.36, P<0.05)$ in this study. On the contrary, fat had a significantly negatively influence on 2-acetylpyrrole formation $(-0.38, P<0.05)$ as it could have reacted with lipid degradation products (J. Zhao, Wang, et al., 2019b). It has been found that dibutyl phthalate as fat-soluble substance can increase if the fat content increases (Cao, 2010). This could explain its significantly positive relationship with fat $(0.32, P<0.05)$ as shown in Fig. 5a. Glycine (Gly) and monosaccharides could react with 2-methoxy-4-vinylphenol to produce an increase in furfural (Jiang, Chiaro, Maddali, Prabhu, \& Peterson, 2009), resulting in a significant negative relationship between Gly and 2-methoxy-4-vinylphenol $(-0.37, P<0.05)$.

The colours are affected by the peanut size as the surface area of large peanut kernels is smaller than those of small kernels at the same weight during roasting. The weight is calculated based on 100 kernels per variety and the higher the weight, the smaller the surface area. As a result, large peanut kernels were roasted to a lower extent, leading to higher $\mathrm{L}^{*}$ values for the peanut butters at the same roasting conditions. Therefore, $\mathrm{L}^{*}$ had a significant positive relationship with weight $(0.32, P<0.05)$ as shown in Fig. 5 a.

Fig. $5 \mathrm{~b}$ shows the correlation between the quality traits of the peanut varieties and the score matrixes from the PCA of the peanut butters in section 3.4. The first five components were regarded as the effective components because their eigenvalues were higher than one (Wang et al., 2020). PC1 had a significant negative relationship with fat $(-0.40$, $P<0.05)$ and a significant positive relationship with sucrose $(0.32, P<$ $0.05)$. This shows that peanut butters processed from the peanut varieties that contained higher sucrose and lower fat contents was situated on the right side of Fig. 4a, corresponding to the positive direction of PC1 which is associated with the contributions from texture, rheology, and pyrazines. The positive direction of PC2 stem from texture, rheology, and $\mathrm{L}^{*}$, while the negative direction of PC2 is attributed to the most volatile compounds (Fig. 4a). PC2 had significant positive relationships with Tyr $(0.40, P<0.05)$, Leu $(0.38, P<0.05)$, and Thr $(0.32, P<0.05)$. In other words, peanut butters processed from the peanut varieties with higher contents of the above-mentioned amino acids normally located on the top side of Fig. 4 a (the positive direction of 
a

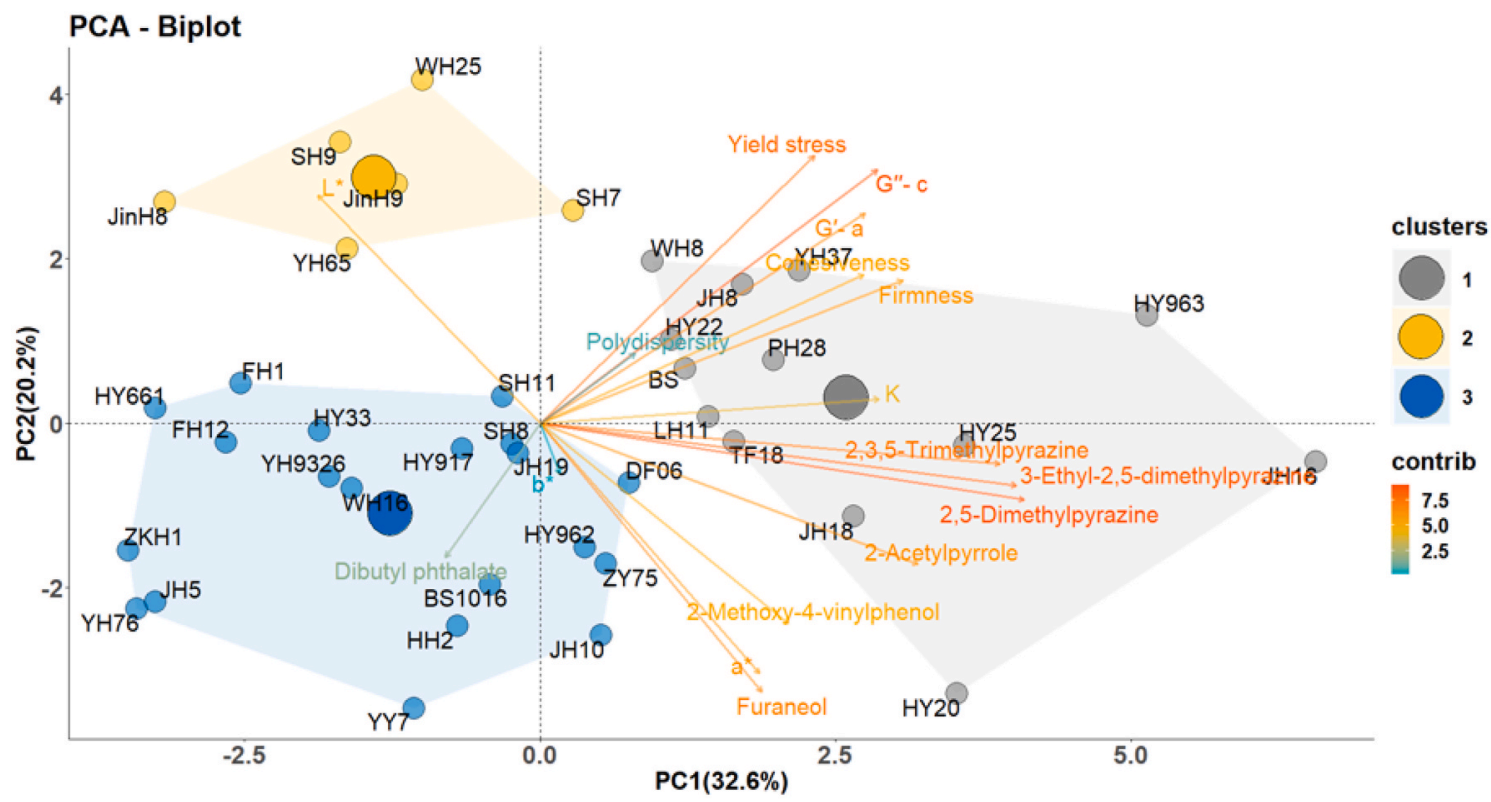

$\mathrm{b}$
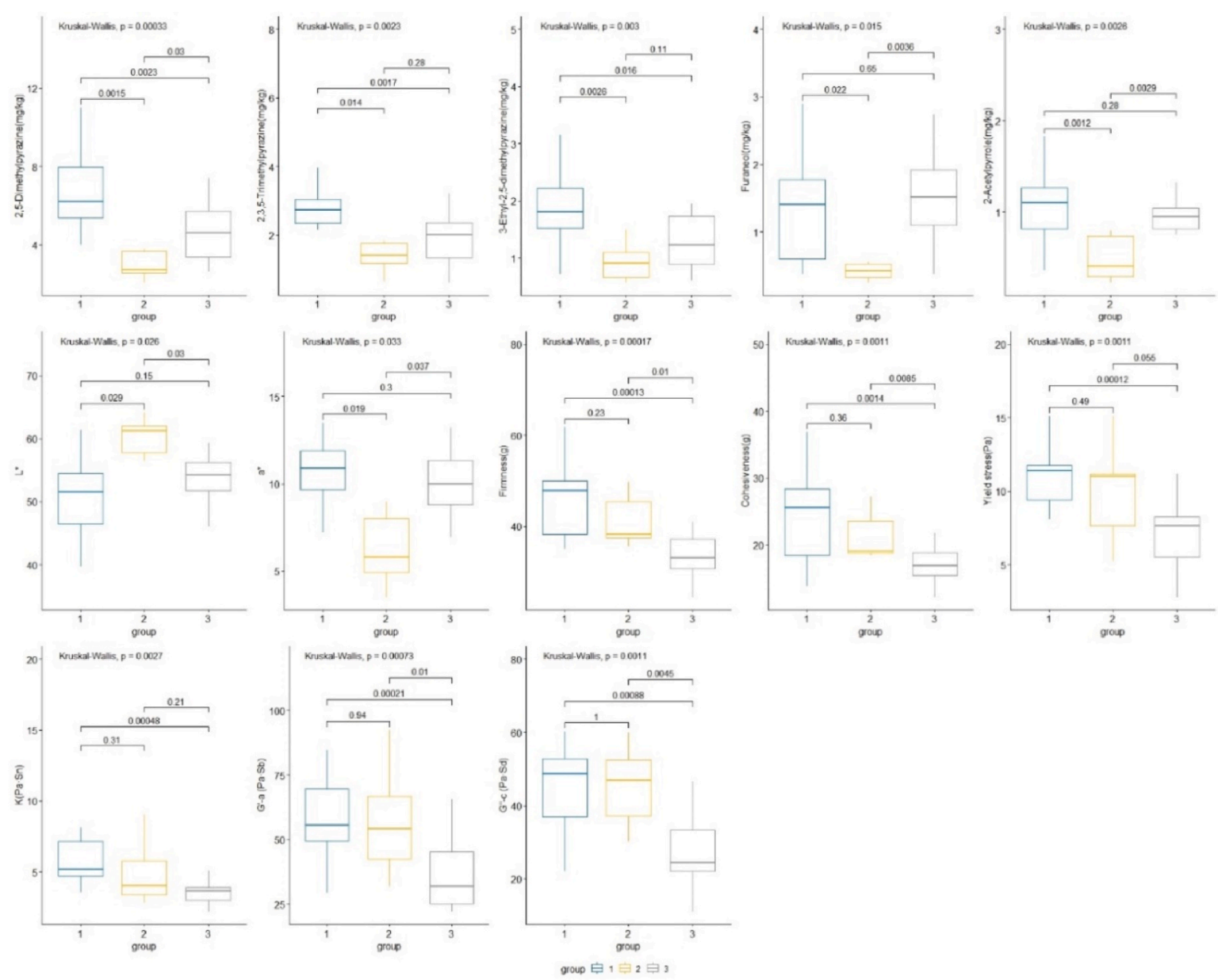

Fig. 4. The (a) principal component analysis (PCA) biplot of the different peanut butters $(n=39)$. The different colored polygons indicate the different sample clusters and arrows indicate the contributions of parameters), and the (b) significantly different qualities of peanut butters in different groups $(P<0.05)$. (contrib) Contribution. 
a

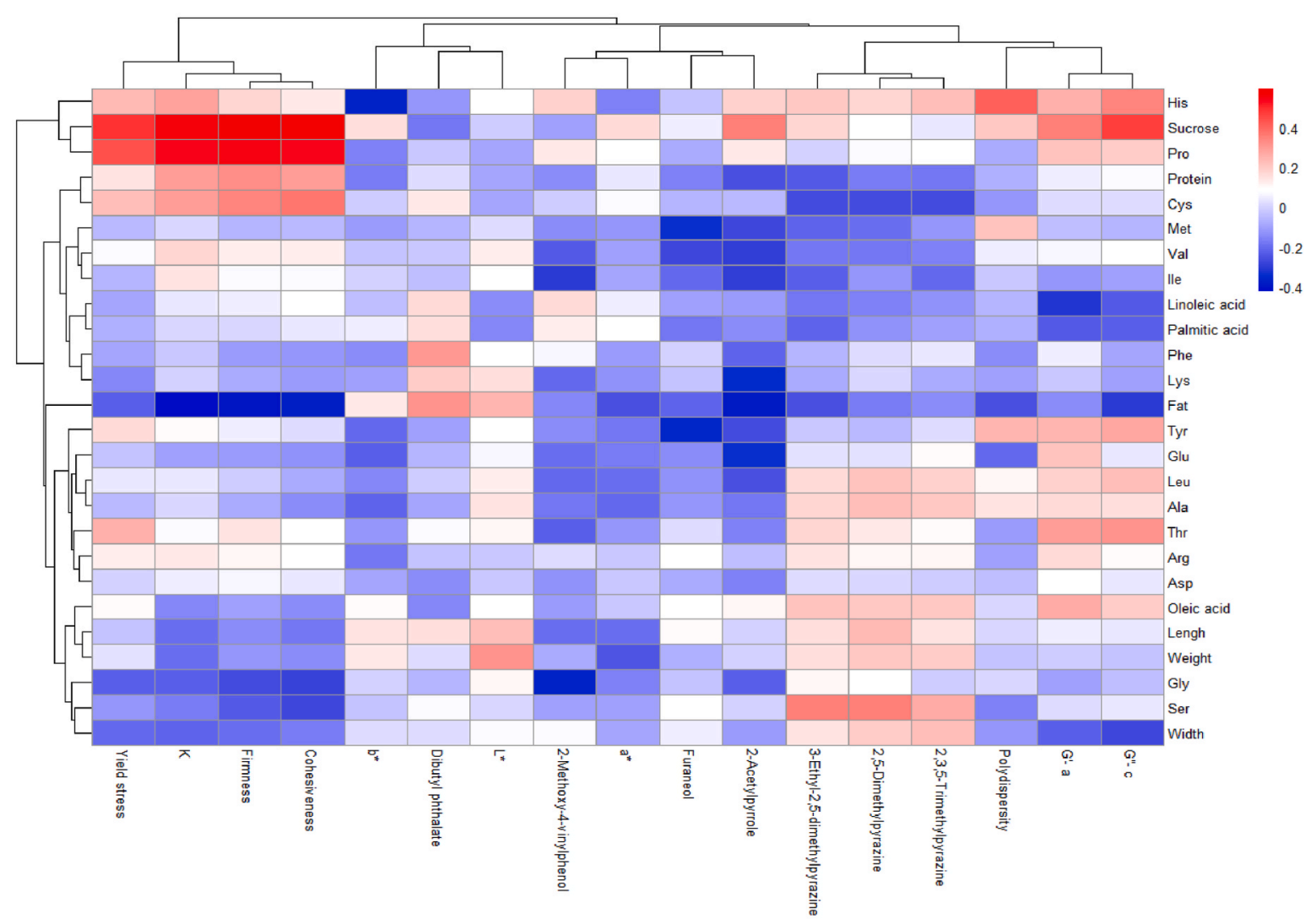

$\mathrm{b}$

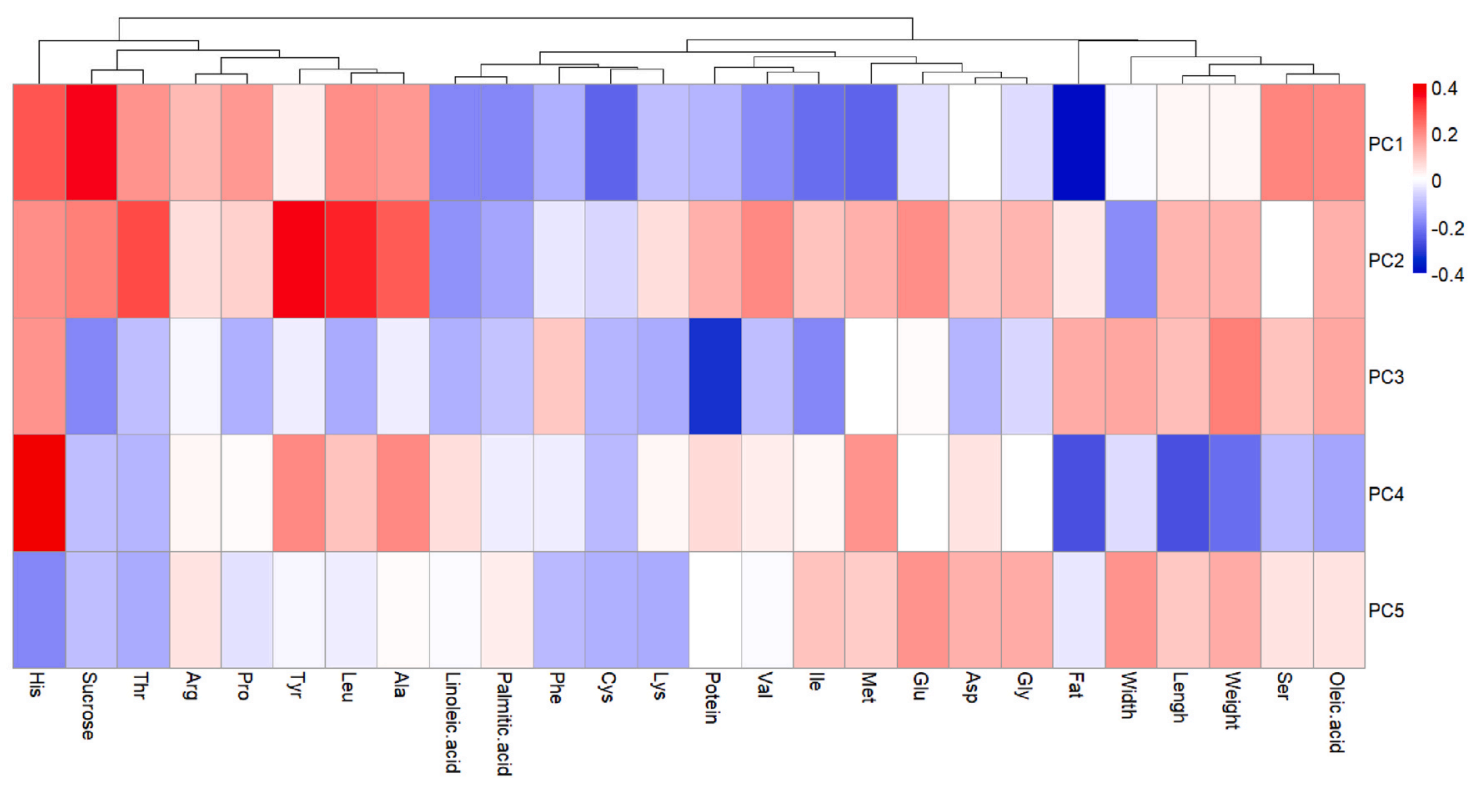

Fig. 5. The (a) correlation analysis between quality traits of the peanut varieties (vertical axis) and qualities of the peanut butter (horizontal axis), and the (b) correlation analysis between the first five principal components of the peanut butters (vertical axis) and quality traits of the peanut varieties (horizontal axis). The positive and negative coefficients are colored red and blue, respectively. Coefficients $<-0.32$ and $>+0.32$ indicate significant correlations $(P<0.05)$. (Ala) Alanine; (Arg) Arginine; (Asp) Aspartic acid; (Cys) Cysteine; (His) Histidine; (Ile) Isoleucine; (Glu) Glutamic acid; (Gly) Glycine; (Leu) Leucine; (Lys) Lysine; (Met) Methionine; (Phe) Phenylalanine; (Pro) Proline; (Ser) Serine; (Thr) Threonine; (Tyr) Tyrosine; (Val) Valine. (For interpretation of the references to colour in this figure legend, the reader is referred to the Web version of this article.) 
PC2).

\section{Conclusions and implications}

A wide diversity in quality traits could be found among the forty peanut varieties. Thereby many heterogeneities in the properties of the peanut butters were discovered based on their volatile compounds, colour, texture, rheology, and particle size distributions. PCA with Kmeans analysis showed different regions with homogeneous characteristics of the peanut butters. Among them, group 1 (HY 25, JH 18, and YH37 etc.) had the highest pyrazines contents and the highest values for texture and rheological properties. In general, it was proposed that the peanut varieties with lower fat, higher protein and sucrose contents could be used to manufacture peanut butters with higher values of the textural and rheological qualities studied; whereas, the peanut varieties with higher sucrose and Ser contents could be used to manufacture peanut butters with higher concentrations of pyrazines and 2-acetylpyrrole, while the heavier peanut varieties with higher Tyr and Thr contents could be used to manufacture peanut butters with higher values of $L^{*}$ and rheological qualities. Instead of focusing on one or two properties from a small data set, this study considered the most important properties of peanut butters that are needed for selecting peanut varieties. This approach will better assist processing enterprises to select the most suitable peanut varieties to produce peanut butters for different commercial needs.

\section{Funding}

This study was supported by the National peanut industry technology system (CARS-13-08B), the Earmarked Fund for Hebei Oil Crop Innovation Team of Modern Agro-industry technology Research System, CAAS-WUR Joint PhD Programme (MOE11NL1A20151701N) and the first author received a scholarship (201903250121) from China Scholarship Council (CSC).

\section{CRediT authorship contribution statement}

Hongwei Yu: Data curation, Formal analysis, Investigation, Methodology, Visualization, Writing - original draft. Hongzhi Liu: Methodology, Supervision, Resources. Sara W. Erasmus: Supervision, Writing - review \& editing. Simeng Zhao: Investigation, Methodology. Qiang Wang: Conceptualization, Funding acquisition, Project administration, Supervision, Resources. Saskia M. van Ruth: Conceptualization, Project administration, Supervision, Writing - review \& editing.

\section{Declaration of competing interest}

The authors declare no conflict of interest.

\section{Acknowledgements}

The authors gratefully acknowledge contributions made by Prof. Xinyou Zhang and other experts from the National Peanut Industry System providing the peanuts for this research, and Jinwu Gu, Dr. Jianxun Li, and Dr. Bo Jiao from Institute of Food Science and Technology (CAAS) for their assistance with the volatile compounds' measurements and rheological analysis.

\section{Appendix A. Supplementary data}

Supplementary data to this article can be found online at https://doi. org/10.1016/j.lwt.2021.112068.

\section{References}

Akkad, R., Kharraz, E., Han, J., House, J. D., \& Curtis, J. M. (2019). Characterisation of the volatile flavour compounds in low and high tannin faba beans (Vicia faba var. minor) grown in Alberta, Canada. Food Research International, 120, 285-294. https:// doi.org/10.1016/j.foodres.2019.02.044

Arrieta-Escobar, J. A., Bernardo, F. P., Orjuela, A., Camargo, M., \& Morel, L. (2019). Incorporation of heuristic knowledge in the optimal design of formulated products: Application to a cosmetic emulsion. Computers \& Chemical Engineering, 122, 265-274. https://doi.org/10.1016/j.compchemeng.2018.08.032

Arsa, S., \& Theerakulkait, C. (2018). Preparation, aroma characteristics and volatile compounds of flavorings from enzymatic hydrolyzed rice bran protein concentrate. Journal of the Science of Food and Agriculture, 98(12), 4479-4487. https://doi.org/ $10.1002 /$ jsfa. 8972

Augusto, P. E. D., Cristianini, M., \& Ibarz, A. (2012). Effect of temperature on dynamic and steady-state shear rheological properties of siriguela (Spondias purpurea L.) pulp. Journal of Food Engineering, 108(2), 283-289. https://doi.org/10.1016/j. jfoodeng.2011.08.015

Baker, G., Cornell, J., Gorbet, D., O'keefe, S., Sims, C., \& Talcott, S. (2003). Determination of pyrazine and flavor variations in peanut genotypes during roasting. Journal of Food Science, 68(1), 394-400. https://doi.org/10.1111/j.1365-2621.2003. tb14171.x

Bayod, E., Willers, E. P., \& Tornberg, E. (2008). Rheological and structural characterization of tomato paste and its influence on the quality of ketchup. LWTFood Science and Technology, 41(7), 1289-1300. https://doi.org/10.1016/j. lwt.2007.08.011

Bishi, S. K., Kumar, L., Dagla, M. C., Mahatma, M. K., Rathnakumar, A. L., Lalwani, H. B., et al. (2013). Characterization of Spanish peanut germplasm (Arachis hypogaea L.) for sugar profiling and oil quality. Industrial Crops and Products, 51, 46-50. https:// doi.org/10.1016/j.indcrop.2013.08.050

Cao, X. L. (2010). Phthalate esters in foods: Sources, occurrence, and analytical methods. Comprehensive Reviews in Food Science and Food Safety, 9(1), 21-43. https://doi.org/ 10.1111/j.1541-4337.2009.00093.x

Chen, B., Li, Q., Hu, H., Meng, S., Shah, F., Wang, Q., et al. (2020). An optimized industry processing technology of peanut tofu and the novel prediction model for suitable peanut varieties. Journal of Integrative Agriculture, 19(9), 2340-2351. https://doi. org/10.1016/s2095-3119(20)63249-x

Citerne, C. P., Pierna, J. C., \& Moan, M. (2001). Rheological properties of peanut butter. Rheologica Acta, 40, 86-96. https://doi.org/10.1007/s003970000120

Dhamsaniya, N. K., Patel, N. C., \& Dabhi, M. N. (2012). Selection of groundnut variety for making a good quality peanut butter. Journal of Food Science \& Technology, 49(1), 115-118. https://doi.org/10.1007/s13197-011-0361-9

GB5009.124. (2016). National food safety standard - determination of amino acid in foods. Beijing: Standard Press of China.

GB5009.168. (2016). National food safety standard- determination of fatty acids in foods. Beijing: Standard Press of China.

GB5009.5. (2016). National food safety standard - determination of protein in foods. Beijing: Standard Press of China.

GB5009.6. (2016). National food safety standard - determination of fat in foods. Beijing: Standard Press of China.

GB5009.8. (2016). National food safety standard - determination of fructose, glucose, sucrose, maltose and lactose in foods. Beijing: Standard Press of China.

van Gemert, L. J. (2011). Odour thresholds: Compilations of odour threshold values in air, water and other media. Utrecht: Oliemans Punter \& Partners.

Gong, A., Shi, A., Liu, H., Yu, H., Liu, L., Lin, W., et al. (2018). Relationship of chemical properties of different peanut varieties to peanut butter storage stability. Journal of Integrative Agriculture, 17(5), 1003-1010. https://doi.org/10.1016/s2095-3119(18) 61919-7

Gudmundsson, M. (2002). Rheological properties of fish gelatins. Journal of Food Science, 67(6), 2172-2176. https://doi.org/10.1111/j.1365-2621.2002.tb09522.x

Ha, J. W., Kim, S. Y., Ryu, S. R., \& Kang, D. H. (2013). Inactivation of Salmonella enterica serovar Typhimurium and Escherichia coli O157:H7 in peanut butter cracker sandwiches by radio-frequency heating. Food Microbiology, 34(1), 145-150. https:// doi.org/10.1016/j.fm.2012.11.018

Hashemian, M., Murphy, G., Etemadi, A., Dawsey, S. M., Liao, L. M., \& Abnet, C. C. (2017). Nut and peanut butter consumption and the risk of esophageal and gastric cancer subtypes. American Journal of Clinical Nutrition, 106(3), 858-864. https://doi. org/10.3945/ajcn.117.159467

Hui, Y. H., Chen, F., Nollet, L. M., Guiné, R. P., Martín-Belloso, O., MínguezMosquera, M. I., ... Sidhu, J. S. (2010). Handbook of fruit and vegetable flavors. Hoboken: John Wiley and Sons.

Hu, W., Zhang, L., Li, P., Wang, X., Zhang, Q., Xu, B., \& Ding, X. (2014). Characterization of volatile components in four vegetable oils by headspace two-dimensional comprehensive chromatography time-of-flight mass spectrometry. Talanta, 129 , 629-635. https://doi.org/10.1016/j.talanta.2014.06.010

Jeong, J. B., \& Jeong, H. J. (2010). 2-Methoxy-4-vinylphenol can induce cell cycle arrest by blocking the hyper-phosphorylation of retinoblastoma protein in benzo[a]pyrenetreated NIH3T3 cells. Biochemical and Biophysical Research Communications, 400(4), 752-757. https://doi.org/10.1016/j.bbrc.2010.08.142

Jiang, D., Chiaro, C., Maddali, P., Prabhu, K. S., \& Peterson, D. G. (2009). Identification of hydroxycinnamic Acid-Maillard reaction products in low-moisture baking model systems. Journal of Agricultural and Food Chemistry, 57(21), 9932-9943. https://doi. org/10.1021/jf900932h

Jiang, H., Duan, N., \& Ren, X. (2006). Specification of peanut germplasm resources. Beijing: China Argricultrue Press. 
Klevorn, C. M., Dean, L. L., \& Johanningsmeier, S. D. (2019). Metabolite profiles of raw peanut seeds reveal differences between market-types. Journal of Food Science, 84(3), 397-405. https://doi.org/10.1111/1750-3841.14450

Koc, H., Vinyard, C. J., Essick, G. K., \& Foegeding, E. A. (2013). Food oral processing: Conversion of food structure to textural perception. Annual Review of Food Science and Technology, 4, 237-266. https://doi.org/10.1146/annurev-food-030212-182637

Levitt, M. (1978). Conformational preferences of amino acids in globular proteins. Biochemistry, 17(20), 4277-4285. https://doi.org/10.1021/bi00613a026

Li, C., \& Hou, L. (2018). Review on volatile flavor components of roasted oilseeds and their products. Grain \& Oil Science and Technology, 1(4), 151-156. https://doi.org/ 10.3724/sp.J.1447.Gost.2018.18052

Lin, H., Liu, Y., He, Q., Liu, P., Che, Z., Wang, X., et al. (2019). Characterization of odor components of Pixian Douban (broad bean paste) by aroma extract dilute analysis and odor activity values. International Journal of Food Properties, 22(1), 1223-1234. https://doi.org/10.1080/10942912.2019.1636816

Liu, Y., Hu, H., Liu, H., Li, J., Yang, Y., Shi, A., \& Wang, Q. (2017). Analysis of volatile compounds in roasted peanut shell and peanut cakes by HS-SPME-GC-MS. Food Science, 2, 139-145.

Liu, X., Jin, Q., Liu, Y., Huang, J., Wang, X., Mao, W., et al. (2011). Changes in volatile compounds of peanut oil during the roasting process for production of aromatic roasted peanut oil. Journal of Food Science, 76(3), 404-412. https://doi.org/ 10.1111/j.1750-3841.2011.02073.x

Liu, Y., Yu, Y., Liu, C., Regenstein, J. M., Liu, X., \& Zhou, P. (2019). Rheological and mechanical behavior of milk protein composite gel for extrusion-based 3D food printing. Lebensmittel-Wissenschaft und -Technologie- Food Science and Technology, 102, 338-346. https://doi.org/10.1016/j.lwt.2018.12.053

Lou, F., Liu, Y., Sun, X., Pan, Y., Zhao, J., \& Zhao, Y. (2009). Identification of volatile flavor components in peanut butter. Food Science (Vol. 24,, 393-396.

Maarse, H. (2017). Volatile compounds in foods and beverages. Boca Raton: CRC Press.

Mathlouthi, M., \& Reiser, P. (2012). Sucrose: Properties and applications. New York: Springer.

Mohd Rozalli, N. H., Chin, N. L., \& Yusof, Y. A. (2015). Particle size distribution of natural peanut butter and its dynamic rheological properties. International Journal of Food Properties, 18(9), 1888-1894. https://doi.org/10.1080/ 10942912.2014.971184

Mohd Rozalli, N. H., Chin, N. L., Yusof, Y. A., \& Mahyudin, N. (2016). Quality changes of stabilizer-free natural peanut butter during storage. Journal of Food Science \& Technology, 53(1), 694-702. https://doi.org/10.1007/s13197-015-2006-X

Nasaruddin, F., Chin, N. L., \& Yusof, Y. A. (2012). Effect of processing on instrumental textural properties of TraditionalDodolUsing back extrusion. International Journal of Food Properties, 15(3), 495-506. https://doi.org/10.1080/10942912.2010.491932

Nayak, S. N., Hebbal, V., Bharati, P., Nadaf, H. L., Naidu, G. K., \& Bhat, R. S. (2020) Profiling of nutraceuticals and proximates in peanut genotypes differing for seed coat color and seed size. [Original research]. Frontiers in Nutrition, 7(45). https://doi org/10.3389/fnut.2020.00045

Nguyen, P. T. M., Kravchuk, O., Bhandari, B., \& Prakash, S. (2017). Effect of different hydrocolloids on texture, rheology, tribology and sensory perception of texture and mouthfeel of low-fat pot-set yoghurt. Food Hydrocolloids, 72, 90-104. https://doi. org/10.1016/j.foodhyd.2017.05.035

Norazatul Hanim, M. R., Chin, N. L., \& Yusof, Y. A. (2016). Effects of grinding time on rheological, textural and physical properties of natural peanut butter stored at different temperatures. Journal of Texture Studies, 47(2), 131-141. https://doi.org/ 10.1111/jtxs.12167

Resch, J. J., \& Daubert, C. R. (2002). Rheological and physicochemical properties of derivatized whey protein concentrate powders. International Journal of Food Properties, 5(2), 419-434. https://doi.org/10.1081/jfp-120005795

Sanders, C. T., DeMasie, C. L., Kerr, W. L., Hargrove, J. L., Pegg, R. B., \& Swanson, R. B. (2014). Peanut skins-fortified peanut butters: Effects on consumer acceptability and quality characteristics. Lebensmittel-Wissenschaft und -Technologie- Food Science and Technology, 59(1), 222-228. https://doi.org/10.1016/j.lwt.2014.04.001

Saputro, A. D., Van de Walle, D., Hinneh, M., Van Durme, J., \& Dewettinck, K. (2018). Aroma profile and appearance of dark chocolate formulated with palm sugar-sucrose blends. European Food Research and Technology, 244(7), 1281-1292. https://doi.org/10.1007/s00217-018-3043-2

Shakerardekani, A., Karim, R., Ghazali, H. M., \& Chin, N. L. (2013). Textural, rheological and sensory properties and oxidative stability of nut spreads-a review. International Journal of Molecular Sciences, 14(2), 4223-4241. https://doi.org/10.3390/ ijms14024223
Starowicz, M., \& Zieliński, H. (2019). How maillard reaction influences sensorial properties (color, flavor and texture) of food products? Food Reviews International, 35 (8), 707-725. https://doi.org/10.1080/87559129.2019.1600538

Stokes, J. R., Boehm, M. W., \& Baier, S. K. (2013). Oral processing, texture and mouthfeel: From rheology to tribology and beyond. Current Opinion in Colloid \& Interface Science, 18(4), 349-359. https://doi.org/10.1016/j.cocis.2013.04.010

Suhui, L., Xuede, W., Yuxiang, M., Jingyuan, L., \& Guozhan, Z. (2019). Preparation of sesame peanut paste and its rheological properties. China Oils and Fats, 2, 147-152.

Taghizadeh, M., \& Razavi, S. M. A. (2009). Modeling time-independent rheological behavior of pistachio butter. International Journal of Food Properties, 12(2), 331-340. https://doi.org/10.1080/10942910701772048

Tamura, H., Fujita, A., Steinhaus, M., Takahisa, E., Watanabe, H., \& Schieberle, P. (2010). Identification of novel aroma-active thiols in pan-roasted white sesame seeds. Journal of Agricultural and Food Chemistry, 58(12), 7368-7375. https://doi. org/10.1021/jf100623a

Tunick, M. H. (2011). Small-strain dynamic rheology of food protein networks. Journal of Agricultural and Food Chemistry, 59(5), 1481-1486.

Wang, Q. (2016). Peanuts: Processing technology and product development. Cambridge: Academic Press.

Wang, Q. (2018). Peanut processing characteristics and quality evaluation. New York: Springer.

Wang, S., Adhikari, K., \& Hung, Y. C. (2017a). Acceptability and preference drivers of freshly roasted peanuts. Journal of Food Science, 82(1), 174-184. https://doi.org/ 10.1111/1750-3841.13561

Wang, X., He, Z., Zeng, M., Qin, F., Adhikari, B., \& Chen, J. (2017b). Effects of the size and content of protein aggregates on the rheological and structural properties of soy protein isolate emulsion gels induced by CaSO4. Food Chemistry, 221, 130-138. https://doi.org/10.1016/j.foodchem.2016.10.019

Wang, L., Liu, H., Liu, L., Wang, Q., Li, S., \& Li, Q. (2017c). Prediction of peanut protein solubility based on the evaluation model established by supervised principal component regression. Food Chemistry, 218, 553-560. https://doi.org/10.1016/j. foodchem.2016.09.091

Wang, Q., Liu, H., Shi, A., Hu, H., Liu, L., Wang, L., et al. (2017d). Review on the processing characteristics of cereals and oilseeds and their processing suitability evaluation technology. Journal of Integrative Agriculture, 16(12), 2886-2897. https:// doi.org/10.1016/s2095-3119(17)61799-4

Wang, F., Meng, J., Sun, L., Weng, Z., Fang, Y., Tang, X., ... Shen, X. (2020). Study on the tofu quality evaluation method and the establishment of a model for suitable soybean varieties for Chinese traditional tofu processing. LWT-Food Science and Technology, 117. https://doi.org/10.1016/j.lwt.2019.108441

Wang, B., Wang, L.-J., Li, D., Özkan, N., Li, S.-J., \& Mao, Z.-H. (2009). Rheological properties of waxy maize starch and xanthan gum mixtures in the presence of sucrose. Carbohydrate Polymers, 77(3), 472-481. https://doi.org/10.1016/j. carbpol.2009.01.017

Wang, L., Wang, Q., Liu, H., Liu, L., \& Du, Y. (2013). Determining the contents of protein and amino acids in peanuts using near-infrared reflectance spectroscopy. Journal of Food Science \& Technology, 93(1), 118-124. https://doi.org/10.1002/jsfa.5738

Yu, H., Liu, H., Erasmus, S. W., Zhao, S., Wang, Q., \& van Ruth, S. M. (2020). Rapid highthroughput determination of major components and amino acids in a single peanut kernel based on portable near-infrared spectroscopy combined with chemometrics. Industrial Crops and Products, 158. https://doi.org/10.1016/j.indcrop.2020.112956

Yu, H., Liu, H., Wang, Q., \& van Ruth, S. (2020). Evaluation of portable and benchtop NIR for classification of high oleic acid peanuts and fatty acid quantitation. Lebensmittel-Wissenschaft und -Technologie- Food Science and Technology. https://doi. org/10.1016/j.lwt.2020.109398, 109398.

Zhang, S., Hu, X., Miao, H., Chu, Y., Cui, F., Yang, W., \& Chen, J. (2019). QTL identification for seed weight and size based on a high-density SLAF-seq genetic map in peanut (Arachis hypogaea L.). BMC Plant Biology, 19(1), 537. https://doi.org/ 10.1186/s12870-019-2164-5

Zhao, Z., Shi, A., Wang, Q., \& Zhou, J. (2019a). High oleic acid peanut oil and extra virgin olive oil supplementation attenuate metabolic syndrome in rats by modulating the gut microbiota. Nutrients, 11(12). https://doi.org/10.3390/nu11123005

Zhao, J., Wang, T., Xie, J., Xiao, Q., Cheng, J., Chen, F., \& Sun, B. (2019b). Formation mechanism of aroma compounds in a glutathione-glucose reaction with fat or oxidized fat. Food Chemistry, 270, 436-444. https://doi.org/10.1016/j. foodchem.2018.07.106

Zhou, D. N., Zhang, B., Chen, B., \& Chen, H. Q. (2017). Effects of oligosaccharides on pasting, thermal and rheological properties of sweet potato starch. Food Chemistry, 230, 516-523. https://doi.org/10.1016/j.foodchem.2017.03.088 